\title{
REVIEW
}

\section{Comparative Effectiveness of Dipeptidylpeptidase-4 Inhibitors in Type 2 Diabetes: A Systematic Review and Mixed Treatment Comparison}

Paul Craddy $\cdot$ Hannah-Jayne Palin $\cdot$ K. Ian Johnson

To view enhanced content go to www.diabetestherapy-open.com

Received: December 20, 2013 / Published online: March 25, 2014

(c) The Author(s) 2014. This article is published with open access at Springerlink.com

\section{ABSTRACT}

Objective: To compare the safety and efficacy of the dipeptidylpeptidase-4 (DPP-4) inhibitors in patients with type 2 diabetes and inadequate glycemic control.

Design: Systematic review of randomized controlled trials (RCTs), health economic evaluation studies, systematic reviews, and meta-analyses, followed by primary Bayesian mixed treatment comparison meta-analyses (MTCs), and secondary frequentist directcomparison meta-analyses using a randomeffects model. Outcomes were reported as weighted mean change from baseline, or odds ratio (OR) with $95 \%$ credible interval.

Data sources: MEDLINE, MEDLINE In-Process, EMBASE, and BIOSIS via Dialog ProQuest; Cochrane Central Register of Controlled Trials

Electronic supplementary material The online version of this article (doi:10.1007/s13300-014-0061-3) contains supplementary material, which is available to authorized users.

P. Craddy

Takeda Pharmaceuticals International GmbH,

Zurich, Switzerland

H.-J. Palin · K. I. Johnson ( $\square)$

McCann Complete Medical, Macclesfield, UK

e-mail: ian.johnson@complete-grp.com and Cochrane Database of Systematic Reviews via EBSCO; four diabetes and two technical congress abstracts; and health technology assessment organization websites.

Eligibility criteria: Patients with type 2 diabetes and inadequate glycemic control receiving any pharmacological anti-diabetic treatment.

Data extraction and analysis: Title/abstracts were reviewed for eligibility, followed by fulltext review of publications remaining after first pass. A three-person team filtered articles and an independent reviewer checked a random selection (10\%) of filtered articles. Data extraction and quality assessment of studies were also independently reviewed. Five DPP-4 inhibitors (alogliptin, linagliptin, saxagliptin, sitagliptin, and vildagliptin) were compared via meta-analysis (where data were available) as monotherapy, dual therapy (plus metformin, sulfonylurea, pioglitazone, or insulin), and triple therapy (plus metformin/sulfonylurea).

Results: The review identified 6,601 articles; 163 met inclusion criteria and 85 publications from 83 RCTs contained sufficient or appropriate data for analysis. MTCs demonstrated no differences between DPP-4 inhibitors in mean change from baseline in 
glycosylated hemoglobin $\left(\mathrm{HbA}_{1 \mathrm{c}}\right)$ or body weight, or the proportions of patients achieving $\mathrm{HbA}_{1 \mathrm{c}}<7 \%$ or experiencing a hypoglycemic event, apart from in patients on alogliptin plus metformin, who achieved $\mathrm{HbA}_{1 \mathrm{c}}$ $<7 \%$ more frequently than those treated with saxagliptin plus metformin [OR 6.41 (95\% CI 3.15-11.98) versus 2.17 (95\% CI 1.56-2.95)].

Conclusions: This systematic review and MTC showed similar efficacy and safety for DPP-4 inhibitors as treatment for type 2 diabetes, either as monotherapy or combination therapy.

Keywords: Alogliptin; DPP-4 inhibitor; Glycosylated hemoglobin; Linagliptin; Mixed treatment comparison; Saxagliptin; Sitagliptin; Type 2 diabetes mellitus; Vildagliptin

\section{INTRODUCTION}

Dipeptidylpeptidase-4 (DPP-4) inhibitors have a mechanism of action that is distinct from other oral glucose-lowering agents [1]. The DPP-4 inhibitor class of oral anti-diabetic agents selectively inhibits the DPP-4 enzyme that rapidly degrades two major incretin hormones, glucagon-like peptide-1 (GLP-1) and glucosedependent insulinotropic polypeptide [2].

Scheen [2] reviewed DPP-4 inhibitors in 2011, analyzing the similarities and differences among members of the DPP-4 inhibitor class of oral antidiabetic agents, including their efficacy and safety profiles as monotherapy or in combination with metformin, a sulfonylurea (SU) and/or a thiazolidinedione, and insulin. The review demonstrated that, although DDP-4 inhibitors produce a similar reduction in glycosylated hemoglobin $\left(\mathrm{HbA}_{1 \mathrm{c}}\right)$ levels compared with other existing classes of oral glucose-lowering agents, DPP-4 inhibitors offer several clinical advantages [3]. These include negligible risk of hypoglycemia, much lower than that observed with SUs, and weight neutrality, compared with the weight gain that is generally associated with SUs and thiazolidinediones [2].

Previous indirect comparisons of the DPP-4 inhibitors in several published meta-analyses [4-8] have reported little or no difference between them with regard to efficacy, both as monotherapy and in combination with other anti-diabetic drugs, and the overall safety profile [2]. However, there are several important differences between the DPP-4 inhibitors with regard to their absorption, distribution, metabolism, and elimination, as well as potency and duration of action [2]. These differences may, potentially, be clinically relevant, particularly in patients with renal or hepatic impairment, and in patients receiving combination therapy, especially those with cardiovascular disease taking multiple drugs [2, 9]. However, there is a lack of head-to-head clinical trials comparing DPP-4 inhibitors: a single clinical trial was identified in the Scheen review [2]. This 18-week trial compared the efficacy of saxagliptin $5 \mathrm{mg}$ and sitagliptin $100 \mathrm{mg}$ in combination with metformin in patients with type 2 diabetes inadequately controlled with metformin alone [10]. The between-group adjusted mean change from baseline in $\mathrm{HbA}_{1 \mathrm{c}}$ demonstrated no difference between saxagliptin and sitagliptin.

Esposito et al. [5] conducted a systematic review and meta-analysis of indirect comparisons of the DPP-4 inhibitors vildagliptin, sitagliptin, saxagliptin, and alogliptin in 2011. The primary outcome of the analysis was the proportion of patients achieving an $\mathrm{HbA}_{1 \mathrm{c}}$ level $<7 \%$, with the absolute change from baseline in $\mathrm{HbA}_{1 \mathrm{c}}$, proportion of patients with hypoglycemic events, and change from baseline in body weight as secondary outcomes. The systematic review of published literature identified no randomized controlled trials (RCTs) with the 
DPP-4 inhibitor linagliptin and was limited to trials published up until September 2010. Separate meta-analyses were conducted for each DPP-4 inhibitor compared with placebo and other antidiabetic agents (including metformin, SUs, pioglitazone, and rosiglitazone) for each of the outcomes.

We have conducted a similar review of DPP-4 inhibitors; as monotherapy compared with placebo, and as dual or triple therapy (where data were available) compared with metformin, SUs, metformin plus SU, pioglitazone, and insulin. Included studies were identified for all pharmacologic therapies for type 2 diabetes. Following this wider review, we extracted data from RCTs in patients treated with a DPP-4 inhibitor and conducted mixed treatment comparison meta-analyses (MTCs) to demonstrate the relative treatment effects of each DPP-4 inhibitor compared with a common comparator, assessing the same four outcomes as reported by Esposito et al. [5].

The aim of the MTCs was to test the hypothesis of no difference between the DPP-4 inhibitors with regard to glycemic control [mean $\mathrm{HbA}_{1 \mathrm{c}}$ change from baseline, proportion of patients achieving target $\left.\mathrm{HbA}_{1 \mathrm{c}}(<7 \%)\right]$, number of patients with hypoglycemic events, and mean change from baseline in body weight.

\section{METHODS}

The analysis in this article is based on previously conducted studies and does not involve any new studies of human or animal subjects performed by any of the authors.

\section{Systematic Literature Search}

We conducted a systematic review of published literature to assess the comparative efficacy and safety of DPP-4 inhibitors compared to other oral and injectable anti-diabetic pharmacologic interventions, including insulin, in the treatment of patients with type 2 diabetes who were receiving monotherapy, dual, or triple therapy. The research question and eligibility criteria for this systematic review conformed to the following PICOS description [11]; studies meeting these criteria were considered for inclusion:

- Population: patients of any age or sex with type 2 diabetes and insufficient glycemic control (including first-, second-, and thirdline treatment regimens).

- Intervention: any DPP-4 inhibitor (alogliptin, linagliptin, saxagliptin, sitagliptin, and vildagliptin), GLP-1 or sodium-glucose cotransporter 2 inhibitors, or pioglitazone used in the treatment of type 2 diabetes (as monotherapy, dual or triple therapy).

- Comparator: any pharmacologic antidiabetic treatment, placebo, or standard of care for diabetes.

- Outcome(s): $\mathrm{HbA}_{1 \mathrm{c}}$ (mean change from baseline and proportion of patients achieving $\mathrm{HbA}_{1 \mathrm{c}}$ target), fasting plasma glucose (FPG), low-density lipoprotein cholesterol, high-density lipoprotein cholesterol, triglycerides, body weight, and hypoglycemia and serious adverse events.

- Study type(s): blinded and open-label RCTs, health economic evaluation studies, systematic reviews, and meta-analyses. Observational studies and retrospective analyses were not included.

Please note that this article focuses on analyses of DPP-4 inhibitors for the following outcomes: mean change in $\mathrm{HbA}_{1 \mathrm{c}}$ from baseline, proportion of patients achieving $\mathrm{HbA}_{1 \mathrm{c}}<7 \%$, mean change from baseline in body weight, and number of patients experiencing a hypoglycemic event. 
Published RCTs, health economic evaluation studies, systematic reviews, and meta-analyses, were identified from a systematic search of electronic databases with no publication date or language restrictions applied. Databases were searched via Dialog ProQuest [12] [MEDLINE and MEDLINE In-Process; EMBASE and BIOSIS for conference abstracts (limited to the previous 3 years)] and EBSCO [13] (Cochrane Central Register of Controlled Trials, Cochrane Database of Systematic Reviews), NHS Economic Evaluation Database [14], and Heath Economic Evaluations Databases [15] for systematic reviews of health economic outcomes. All electronic databases were searched on November 30, 2012. Reference lists of selected systematic reviews and metaanalyses meeting the inclusion criteria were reviewed to identify further studies, including unpublished studies. 'Grey literature' searches were also conducted of relevant congresses (American Diabetes Association [16], European Association for the Study of Diabetes [17], International Diabetes Federation [18], Canadian Diabetes Association [19], Health Technology Assessment (HTA) International [20] and International Society for Pharmacoeconomics and Outcomes Research [21]), limited to the previous 3 years. Other appropriate sources searched included the ClinicalTrials.gov website of the US National Institutes of Health [22], and HTA databases including those from the International Network of Agencies for Health Technology Assessment [23], National Institute for Health and Care Excellence (NICE) [24], National Institute for Health Research [25], and Canadian Agency for Drugs and Technologies in Health [26]. A structured search string was employed, including terms for type 2/non-insulin dependent diabetes mellitus and drug therapy. Specific filters for retrieving RCTs conducted in humans, meta-analyses, systematic reviews, and health economic evaluation studies were incorporated into the search string. The full search string is presented in Appendix 1 (Electronic Supplementary Material).

Any abstracts associated with full-text articles were identified. If more than one article presented data from the same study population, only data from the most recent full-text publication were included. If a conference abstract superseded a full-text publication, data from outcomes presented in the conference abstract that were not included in the full-text publication were utilized.

\section{Study Selection}

Identified articles were screened to ensure they met predetermined inclusion criteria. Each reviewer was provided with a checklist based on the inclusion/exclusion criteria specified in the systematic review protocol (Commercial in confidence), and a structured Microsoft Excel (Microsoft Corp, Redmond, WA, USA) spreadsheet was used to ensure uniformity of appraisal for each study. Initially, titles or abstracts (or both) of all identified citations were reviewed according to a first-pass checklist. Fulltext publications of the citations remaining after the first pass were then reviewed according to a second-pass checklist. A three-person team reviewed the articles at first and second pass, and an independent reviewer checked a random selection (10\%) of filtered articles for consistency.

A positive exclusion method was used, whereby studies for which there were insufficient information for exclusion remained in the review until a stage where it could be proven that they did not meet the inclusion criteria.

Although the systematic review included all pharmacologic treatments for type 2 diabetes, 
in this paper we report only the analyses of DPP-4 inhibitors.

\section{Data Extraction}

The Microsoft Excel spreadsheet designed to ensure uniformity of appraisal was subsequently used to capture all relevant data for included studies. All data extracted for meta-analysis were also independently reviewed and reviewers came to a consensus regarding the final data recorded for each study. Data input sheets for the meta-analyses, including data imputations, were also checked for accuracy by a second reviewer prior to conducting the analyses. Extracted data consisted of study characteristics [such as study design, duration, primary and secondary endpoints, study inclusion and exclusion criteria, treatment and dose (including schedule and strategy), and patient baseline characteristics (age, comorbidities, renal impairment, cardiovascular risk, concomitant medications, and disease duration)]. Extracted data were grouped such that information for different treatment regimens could be easily identified.

\section{Assessment of Data for Meta-analysis}

Studies were assessed to establish whether sufficient and appropriate data were reported for the relevant outcomes. Studies were excluded based on the following criteria: article reported extension phase of an RCT already included; lack of common comparator (i.e., no connection within treatment network); inappropriate patient population (e.g., patients with adequate glycemic control, mixed population with type 1 diabetes); insufficient data for standard error imputation (i.e., patient numbers not given); cross-over study; and duplicate data.

\section{Quality Assessment}

Studies from which data were extracted were assessed for robustness as sources of information for inclusion in subsequent statistical analyses. Quality assessment was conducted according to the methods and assessment instruments recommended by the HTA authorities in France, Germany, Italy, Spain, UK, USA, and Canada. Hierarchical assessment of the risk of bias was conducted as recommended by the Institute for Quality and Efficiency in Health Care (Germany) in their guidelines on methods for conducting systematic reviews [27], checklist criteria recommended by l'Agence nationale d'accréditation et d'évaluation en santé (France) in their guide to the literature and grading of recommendations [28], and qualityassessment criteria recommended by NICE (UK) in their single technology appraisal template [29]. Study quality was also independently reviewed. Clinical trials were also evaluated to assess whether they had been reported according to the Consolidated Standards of Reporting Trials [30] checklist. Study quality was not used as an inclusion/exclusion criterion or to weight individual studies in the metaanalyses.

\section{Data Imputation}

Where studies did not explicitly report standard errors, these were derived from available published information. If possible, standard errors were obtained from confidence intervals (CIs) and standard deviations (SDs); if these data were unavailable, they were derived from the $p$ value referring to the change from baseline. If none of the above was available, standard errors were imputed using data from other wellreported studies, using methods outlined by 
the Cochrane Collaboration [31]. Alternatively, as a final option, if there was no other wellreported study, $p$ values for the difference between treatments were used and the pooled SD applied to both arms. Mean changes from baseline values were derived by subtracting before and after values, if not explicitly stated.

\section{Quantitative Analysis}

Direct evidence was assessed by conducting random-effects meta-analyses in a frequentist setting in Stata (Version 12; StataCorp, College Station, TX, USA) for each DPP-4 inhibitor (as monotherapy, dual and triple therapy) against common comparator arms. In studies reporting results for multiple DPP-4 inhibitor doses, only data related to the licensed dose were included in the analysis. Data were presented as the effect estimate and 95\% CI. Heterogeneity was assessed using the $I^{2}$ statistic, i.e., the percentage of the variability in effect estimates due to heterogeneity rather than sampling error. Interpretation of the $I^{2}$ statistic was in accordance with the Cochrane Collaboration recommendations [31]. For direct comparisons that reported $I^{2}$ values $>30 \%$, sensitivity analyses were considered and were conducted where outliers were identified to assess robustness of the pooled effect estimate.

Mixed treatment comparison meta-analyses were also performed to demonstrate the relative treatment effects of each DPP-4 inhibitor (as monotherapy, dual or triple therapy) using a Bayesian framework and Markov chain Monte Carlo methods, which were fitted using the Bayesian software in WinBUGS (Medical Research Council Biostatistics Unit, Cambridge, UK) [32]. This allowed for direct evidence (within-trial comparisons between treatments) and indirect evidence (treatments within different trials with a common comparator) to be considered simultaneously.

Typically, models consisted of 100,000 iterations with a 50\% burn-in sample. Standard diagnostics tools were used to assess convergence to the stationary distribution. This included observing random walk plots for each node and assessment of the Gelman-Rubin diagnostic statistic. The rejection sampler followed the standard hierarchy of sampling methods in the WinBUGS program [32]. Initial values were generated randomly for different chains to assess the robustness of different starting values. Random-effects models were utilized to account for heterogeneity from varying study populations.

Mean changes from baseline in $\mathrm{HbA}_{1 \mathrm{c}}$ and body weight outcomes are both continuous measures. These were estimated using a vague prior normal distribution, allowing the data to have maximum leverage over the iterative process. Data were presented as a weighted mean difference between treatments. Proportions of patients with $\mathrm{HbA}_{1 \mathrm{c}}<7 \%$ and hypoglycemic-event outcome measures are binomial (the outcome is either achieved or not). For this type of data, the probability of the outcome was modeled using a binomial distribution. Each pair of treatments was compared by estimating the odds ratio (OR) of the outcome. Each study within each randomeffects meta-analysis had a weight based on the within-study variation. It was assumed that each log OR had been sampled from a normal distribution and that the treatment effects were wholly exchangeable within studies.

Data for all DPP-4 inhibitor and comparator doses were included in the analyses for studies that reported multiple doses. All data were presented as an effect estimate and 95\% credible interval, with $95 \%$ credible intervals 
Table 1 Comparator meta-analysis estimates of treatment effect for input into the calculation of absolute treatment effect

\begin{tabular}{lc}
\hline Comparator & $\begin{array}{l}\text { Comparator estimate } \\
\text { treatment effect mean } \\
\text { (standard error) }\end{array}$ \\
\hline Placebo & $0.18(0.06)$ \\
Metformin & $-0.421(0.02)$ \\
Sulfonylurea & $-0.065(0.036)$ \\
Metformin plus sulfonylurea & $-0.033(0.038)$ \\
Pioglitazone & $-0.657(0.032)$ \\
Insulin & $-0.155(0.069)$ \\
\hline
\end{tabular}

that did not include zero deemed statistically significant. Overlapping 95\% credible intervals were considered as evidence of no difference between treatments.

Mixed treatment comparison meta-analyses were conducted for absolute and relative (vs. comparator) treatment effects. Absolute treatment-effect calculations required an estimate for the efficacy of the comparator arm to be entered into the MTC. Directcomparison meta-analyses were conducted to obtain more accurate estimates of the comparator treatment effects (see Table 1).

\section{Consistency Between Direct and Indirect Data}

The consistency of direct and indirect comparisons was assessed for nodes comparing DPP-4 inhibitors directly. A single study reported direct comparison data of two DPP-4 inhibitors (sitagliptin and saxagliptin) plus metformin. Thus, consistency tests assessing the relationship between sitagliptin plus metformin and saxagliptin plus metformin for mean change from baseline $\mathrm{HbA}_{1 \mathrm{c}}$ and proportion of patients achieving $\mathrm{HbA}_{1 \mathrm{c}}<7 \%$ were conducted using Bucher's extended method for multiple loops [33]. Bucher's method for multiple loops combines direct and indirect evidence for multiple pathways and these multiple loops construct a $\chi^{2}$ test statistic. The $p$ value attained from the calculated $\chi^{2}$ statistic gives the probability of observing a test statistic at least as extreme as the calculated value, given the null hypothesis of consistency between direct and indirect evidence is true. If this $p$ value is $<0.01$, typically, this hypothesis is rejected [33].

\section{RESULTS}

\section{Data Selection}

Figure 1 shows the selection process for articles in the systematic review and meta-analyses. Seventy-eight studies were excluded since they were deemed to contain insufficient or inappropriate data based upon criteria described in the "Methods" [see Appendix 2 for a listing (Electronic Supplementary Material)].

Sixty non-English articles proceeded to second pass, of which only two reported results of an RCT with a DPP-4 inhibitor. Both of these articles included the DPP-4 inhibitor, anagliptin, which is only licensed in Japan and was only reported in these two articles. Thus, it was not eligible for inclusion in the mixed treatment comparison network and was excluded from the analysis.

\section{Characteristics of Included Studies}

Appendix 3 (Electronic Supplementary Material) provides details of the 83 RCTs included. Of these, 82 compared DPP-4 inhibitor treatment regimens with placebo, metformin $( \pm S U$, pioglitazone or insulin), SU, pioglitazone, or insulin, while one directly compared sitagliptin plus metformin with saxagliptin plus 


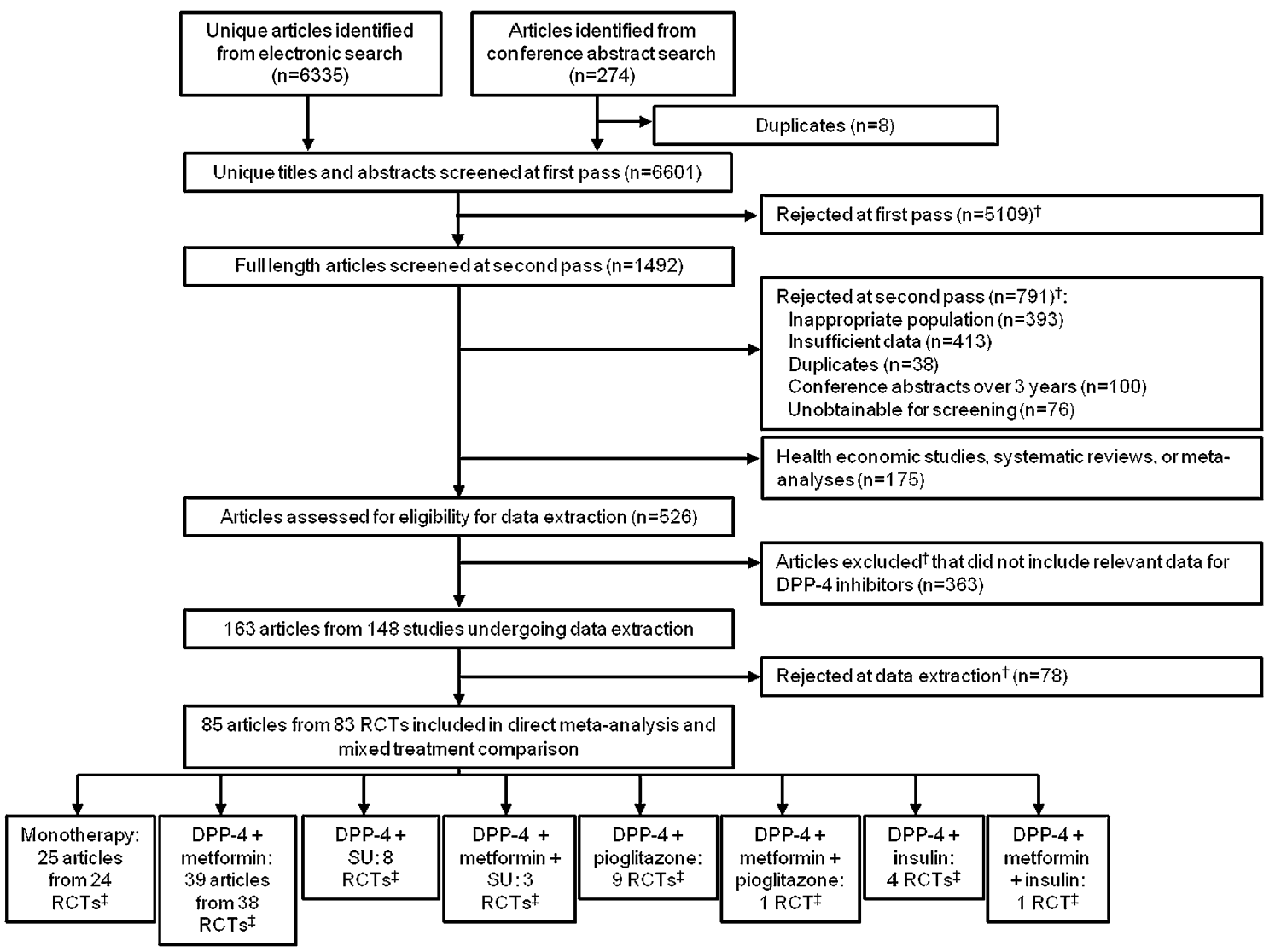

Fig. 1 Number of articles proceeding at each stage of the systematic review. ${ }^{\dagger}$ Articles excluded for more than one reason. Number of RCTs does not add up to 83 as each

metformin [10]. All RCTs were included in at least one of the analyses; each RCT could be used in multiple sets of analyses.

Quality assessment of studies for which data were extracted (Appendix 4, Electronic Supplementary Material) indicated two studies that represented high-quality or robust sources of information [34, 35], as they were deemed to be of high quality by all quality-assessment criteria. However, it is worth noting that the majority of studies from which data were extracted and subsequently included in the statistical analyses were deemed to have three or fewer 'unclear' ratings, which could potentially indicate that the level of reporting was not sufficient to determine an accurate
RCT could be used in multiple sets of analyses. DPP-4 dipeptidylpeptidase- 4 inhibitor, $R C T$ randomized controlled trial, $S U$ sulfonylurea

assessment of robustness. Ten studies were assessed as representing low-quality or nonrobust sources of information [36-46]; however, all were deemed to have two or more 'unclear' ratings and only a single study [40] was included in the subsequent statistical analysis.

The majority of RCTs were double blind. However, five articles reported data from openlabel RCTs [36, 47-50]. Trial durations varied widely-from 4 weeks to 104 weeks. Two studies included an initial 12-week randomization stage followed by a 40-week extension [34, 51].

Inclusion criteria for the majority of trials included baseline $\mathrm{HbA}_{1 \mathrm{c}}$ levels of $6.0-11.0 \%$. However, a number of trials included patients with higher baseline $\mathrm{HbA}_{1 \mathrm{c}}$ levels, which might 
have resulted in greater $\mathrm{HbA}_{1 \mathrm{c}}$ reductions during the study. Indeed, baseline $\mathrm{HbA}_{1 \mathrm{c}}$ levels reported by Pfützner et al. [52] were 8.0-12.0\%, Derosa et al. [53] $>8.0 \%$, Pérez-Monteverde et al. [54] 7.5-12.0\%, Wainstein et al. [55] 7.5-12.0\%, Jadzinsky et al. [56] 8.0-12.0\%, and Yoon et al. [57] 8.0-12.0\%. The majority of trials included patients with body mass index (BMI) $\leq 40 \mathrm{~kg}$ / $\mathrm{m}^{2}$. However, 7 trials included patients with a lower maximum baseline BMI [53, 58-63] and 18 trials included patients with a higher maximum baseline BMI [35, 47, 48, 64-78]. Increased BMI outside the normal range (BMI $18.5-25.0 \mathrm{~kg} / \mathrm{m}^{2}$; healthy weight), as classified by the World Health Organization [79], is associated with type 2 diabetes and comorbid conditions including hypertension and dyslipidemia. The mean age of patients was similar between studies, apart from four studies $[63,73,80,81]$, in which the mean age of patients was $\geq 65$ years. Elderly patients may have many comorbid conditions or functional disabilities and may take multiple additional medications (polypharmacy).

In the majority of trials, the primary outcome was mean change in $\mathrm{HbA}_{1 \mathrm{c}}$ from baseline to endpoint. However, eight trials reported coprimary outcomes to $\mathrm{HbA}_{1 \mathrm{c}}$ change from baseline $[54,59,62,64,82-85]$, such as change from baseline in FPG, 2-hour postprandial glucose, BMI, body weight, fasting lipids, fasting plasma insulin, fasting insulin, fasting C-peptide, vital signs, and number/proportion of patients with adverse events, homeostatic model assessment-insulin resistance ( $\beta$-cell function), and proportion of patients achieving $\mathrm{HbA}_{1 \mathrm{c}}<7 \%$. In five trials, $\mathrm{HbA}_{1 \mathrm{c}}$ change from baseline was not the primary outcome $[36,53,68,86,87]$. Instead, the primary outcome was another blood glucose measure (e.g., postprandial blood glucose and change from baseline in 24-h weighted mean glucose), postprandial GLP-1 response, change in insulin secretion at endpoint, or change from baseline in postprandial incremental analytical ultracentrifugation for total plasma triglycerides.

\section{Direct-comparison Meta-analyses and Mixed Treatment Comparisons}

The quantitative analyses investigated the difference between treatments in the mean change from baseline $\mathrm{HbA}_{1 \mathrm{c}}$, OR for proportion of patients achieving $\mathrm{HbA}_{1 \mathrm{c}}$ target $(<7 \%)$, mean change from baseline in body weight, and OR for the number of patients reporting a hypoglycemic event.

First, the direct evidence was assessed by conducting random-effects meta-analyses for each DPP-4 inhibitor (as monotherapy, dual or triple therapy) against placebo, metformin, SU, metformin plus SU, pioglitazone, metformin plus pioglitazone, insulin, and metformin plus insulin. MTCs were then developed from the network of DPP-4 inhibitor trials identified in the systematic review. Eligible network comparisons for $\mathrm{HbA}_{1 \mathrm{c}}$ mean change from baseline for DPP-4 inhibitors (as monotherapy, dual or triple therapy) are presented in Fig. 2. As an example, we have presented the networks for $\mathrm{HbA}_{1 \mathrm{c}}$ mean change from baseline in this paper as these represent the most complex treatment networks and include the majority of trials (networks for the proportion of patients achieving $\mathrm{HbA}_{1 \mathrm{c}}$ level $<7 \%$, mean change from baseline in body weight, and proportion of patients experiencing a hypoglycemic event are available on request).

Individual study data for each of the four outcomes analyzed in the meta-analyses are summarized in Table 2 [10, 34-36, 40, 47-127].

Direct-comparison meta-analysis results are presented in Tables 3 and 4 for continuous and binominal outcomes, respectively. Results of the relative and absolute treatment effects in the MTCs are presented in Tables 5 and 6, respectively. 

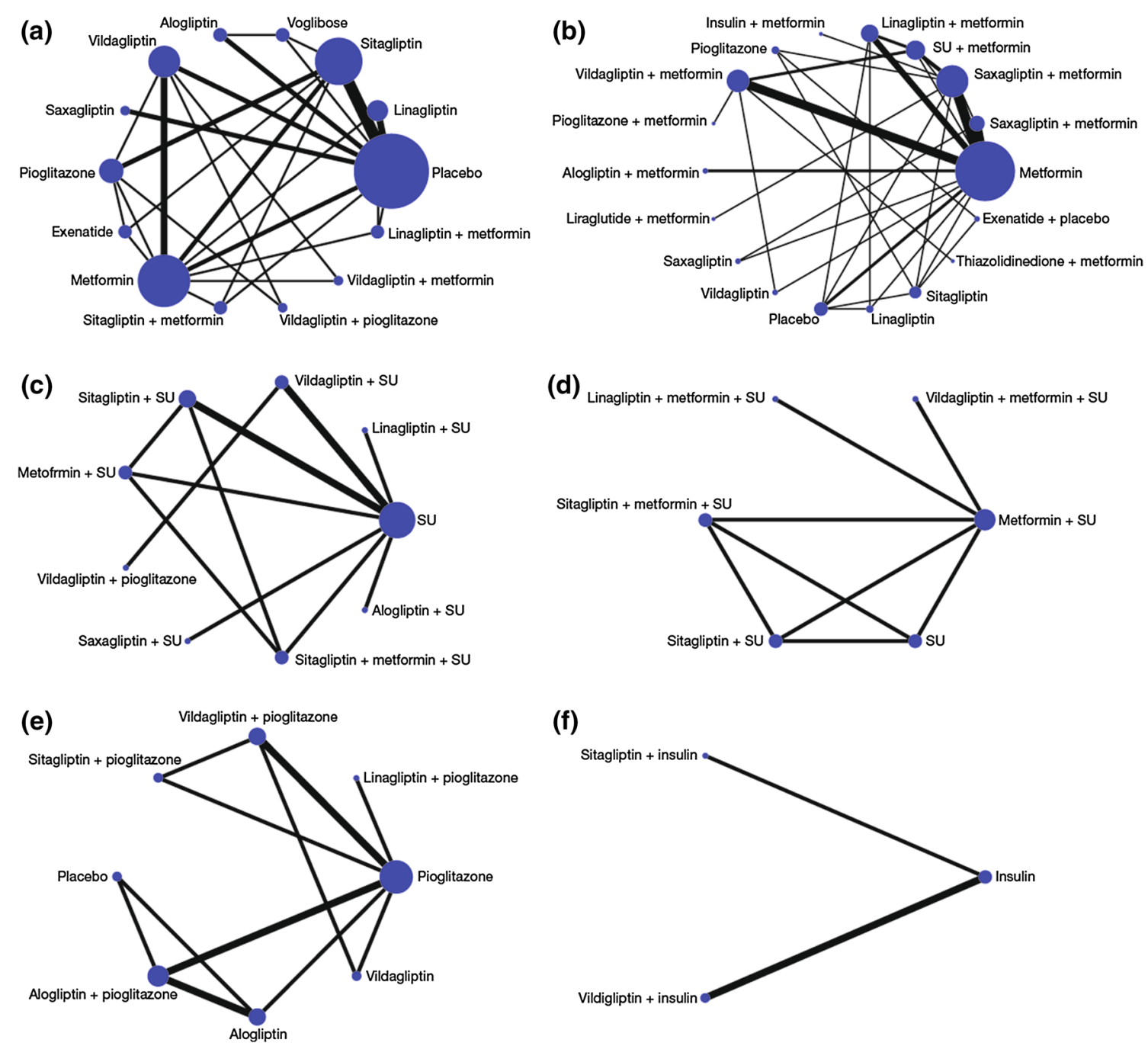

(f)

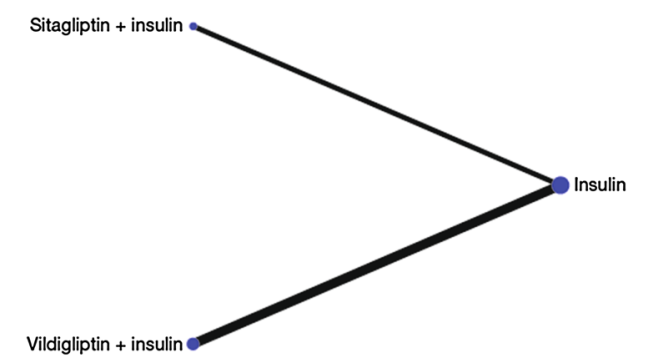

Fig. 2 Networks of eligible comparisons for $\mathrm{HbA}_{\mathrm{lc}}$ mean change from baseline for a DPP-4 monotherapy, b DPP-4 plus metformin, c DPP-4 plus SU, d DPP-4 plus metformin plus SU, e DPP-4 plus pioglitazone, and f DPP-4 plus insulin. The width of the lines is proportional

\section{DPP-4 Monotherapy}

In the direct-comparison analysis, all DPP-4 inhibitors were significantly more effective than placebo in achieving a greater mean reduction from baseline in $\mathrm{HbA}_{1 \mathrm{c}}$ and a greater proportion of patients achieved $\mathrm{HbA}_{1 \mathrm{c}}$ levels $<7 \%$ (Tables 3 , 4). However, the $I^{2}$ statistic for linagliptin studies in the $\mathrm{HbA}_{1 \mathrm{c}}$ change from baseline analysis (33.0\%) may represent moderate heterogeneity, and the $I^{2}$ statistic for

to the number of trials comparing each pair of treatments, and the size of each node is proportional to the number of trials for each treatment. DPP-4 dipeptidylpeptidase- 4 inhibitor, $H b A_{1 c}$ glycosylated hemoglobin, $S U$ sulfonylurea

sitagliptin studies in the $\mathrm{HbA}_{1 \mathrm{c}}<7 \%$ analysis $(63.7 \%)$ may represent substantial heterogeneity, in the effect estimates.

The relative treatment effects in the MTC analysis showed that DPP-4 inhibitors as monotherapy were significantly more effective than placebo at reducing mean $\mathrm{HbA}_{1 \mathrm{c}}$ from baseline (Table 5). Patients treated with any of the DPP-4 inhibitors, except for saxagliptin, were statistically significantly more likely to 


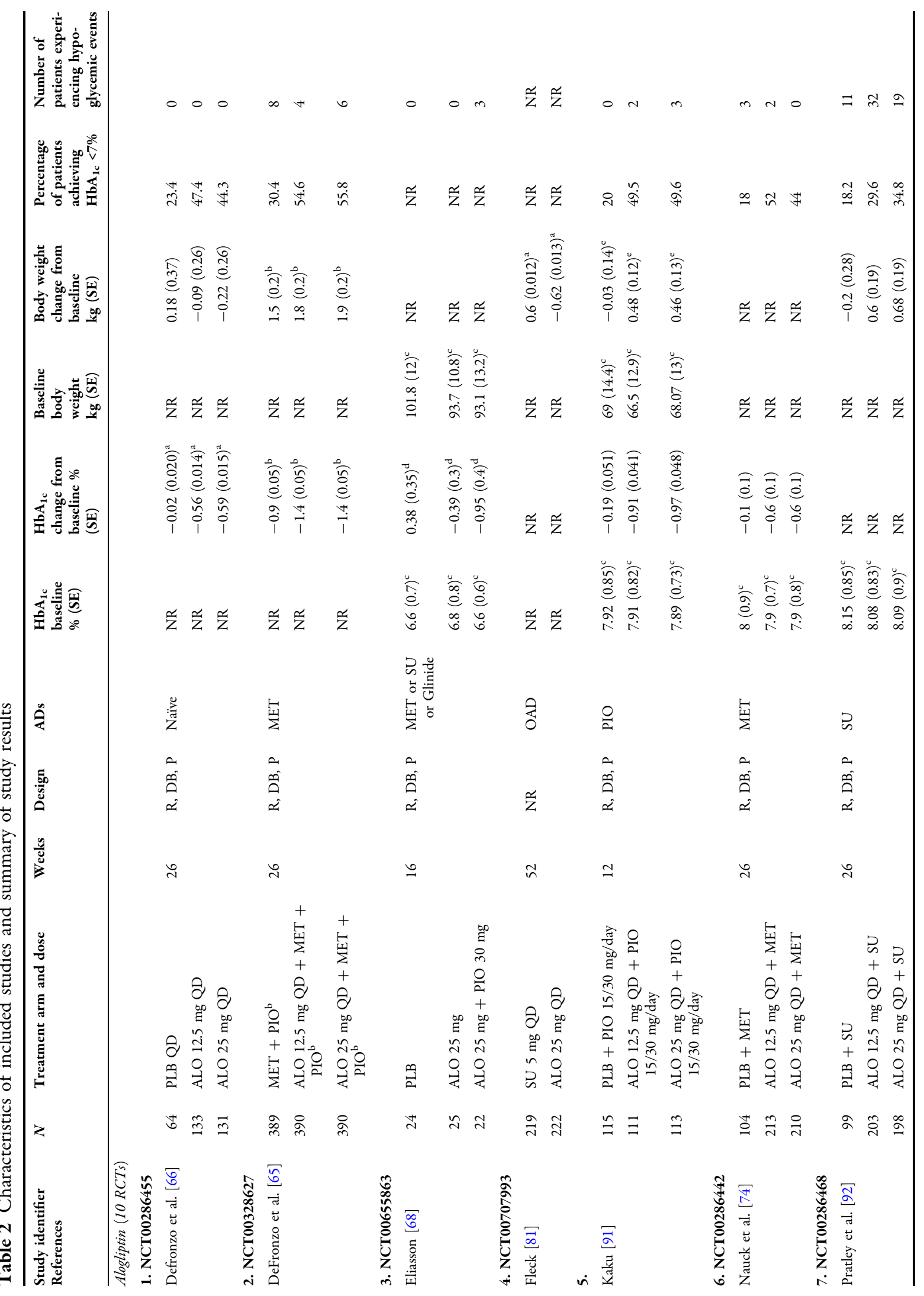




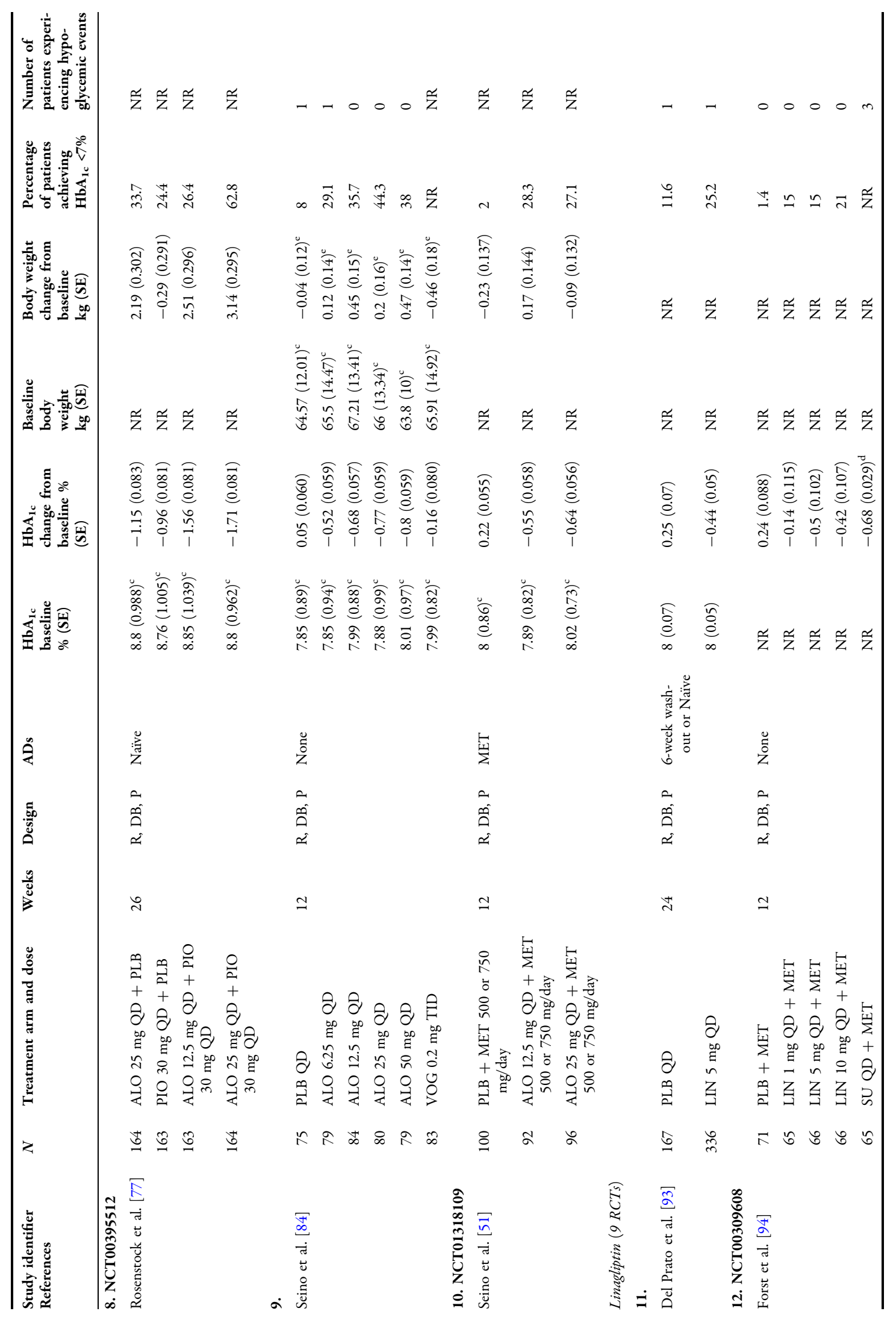




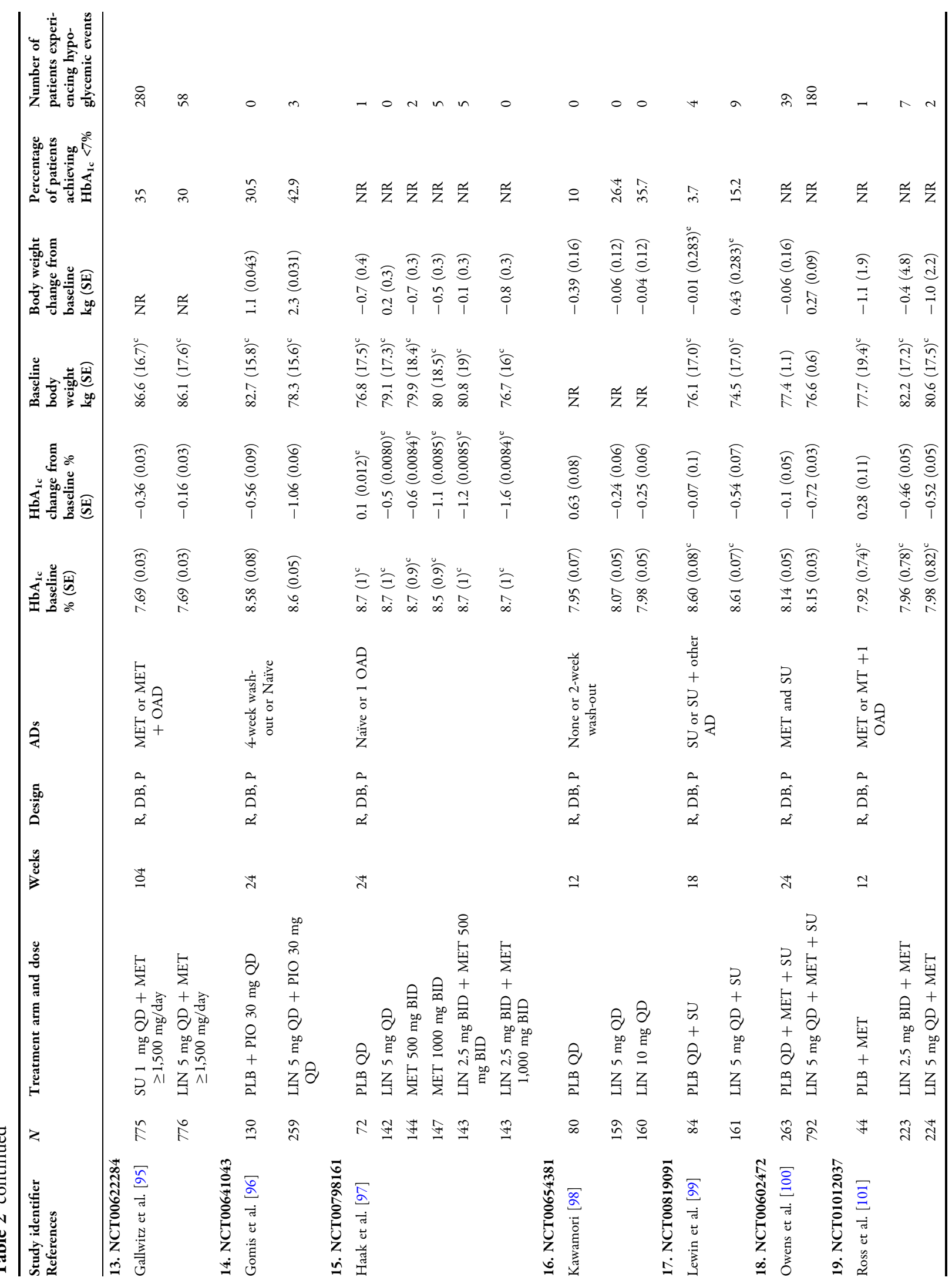




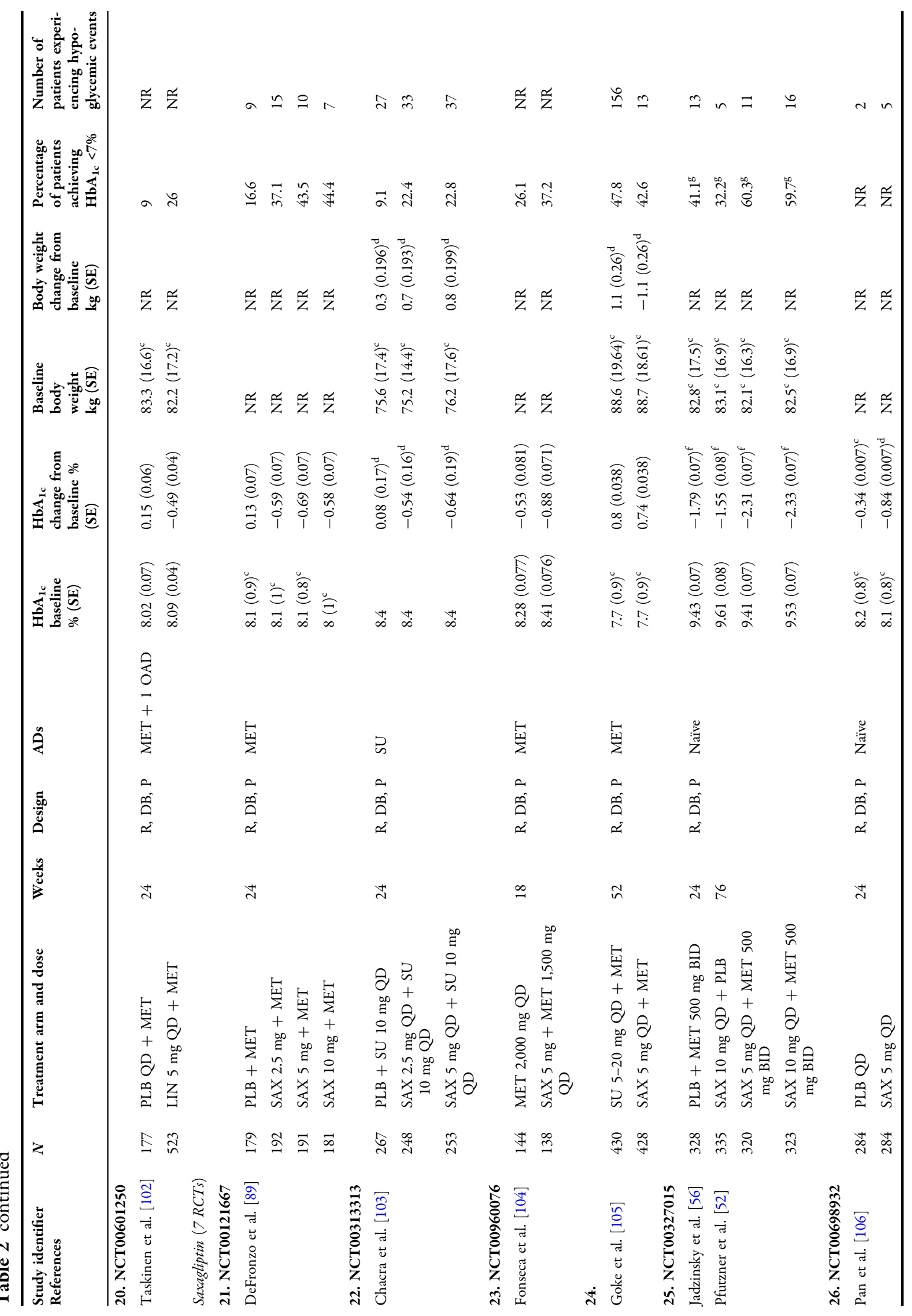




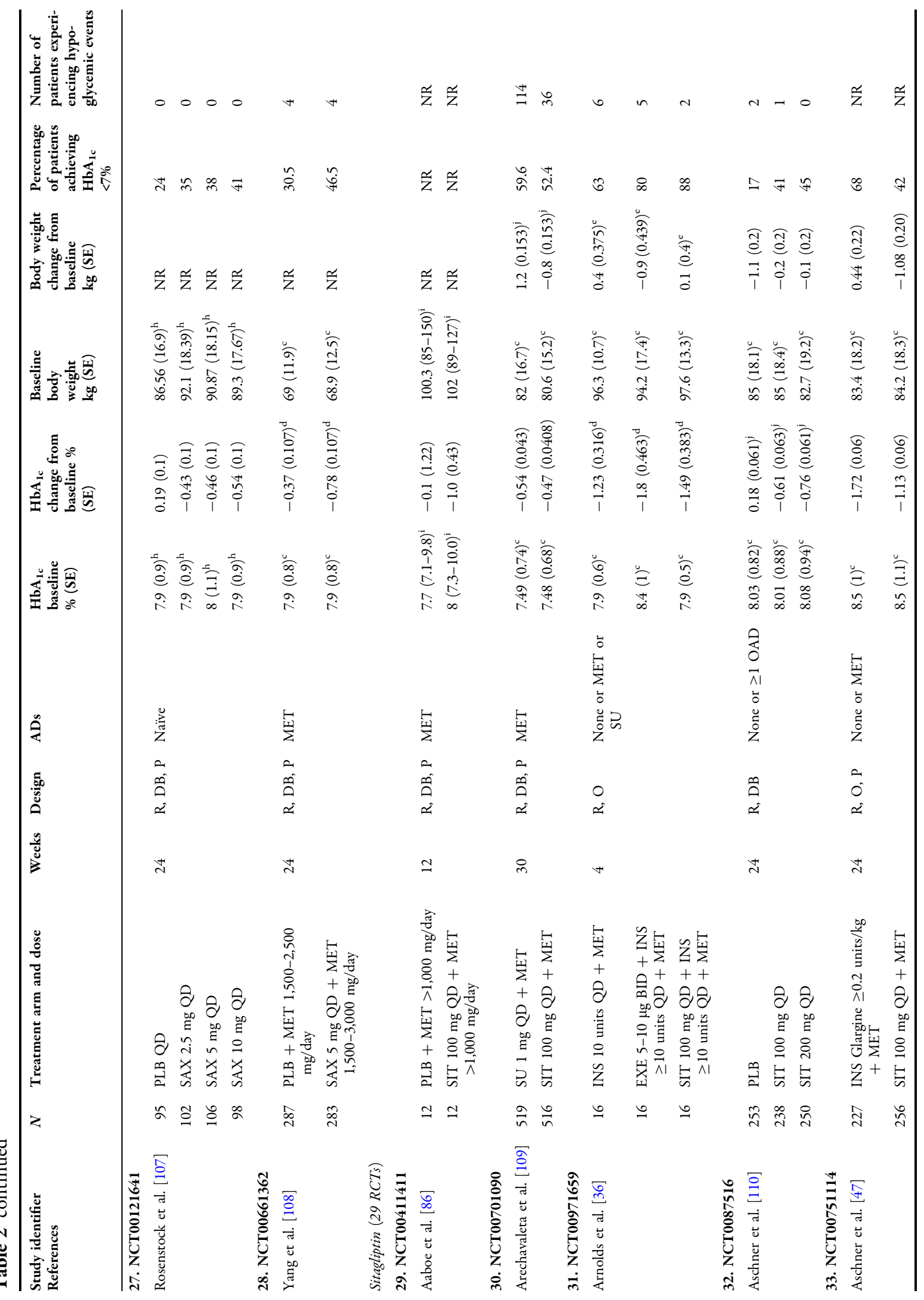




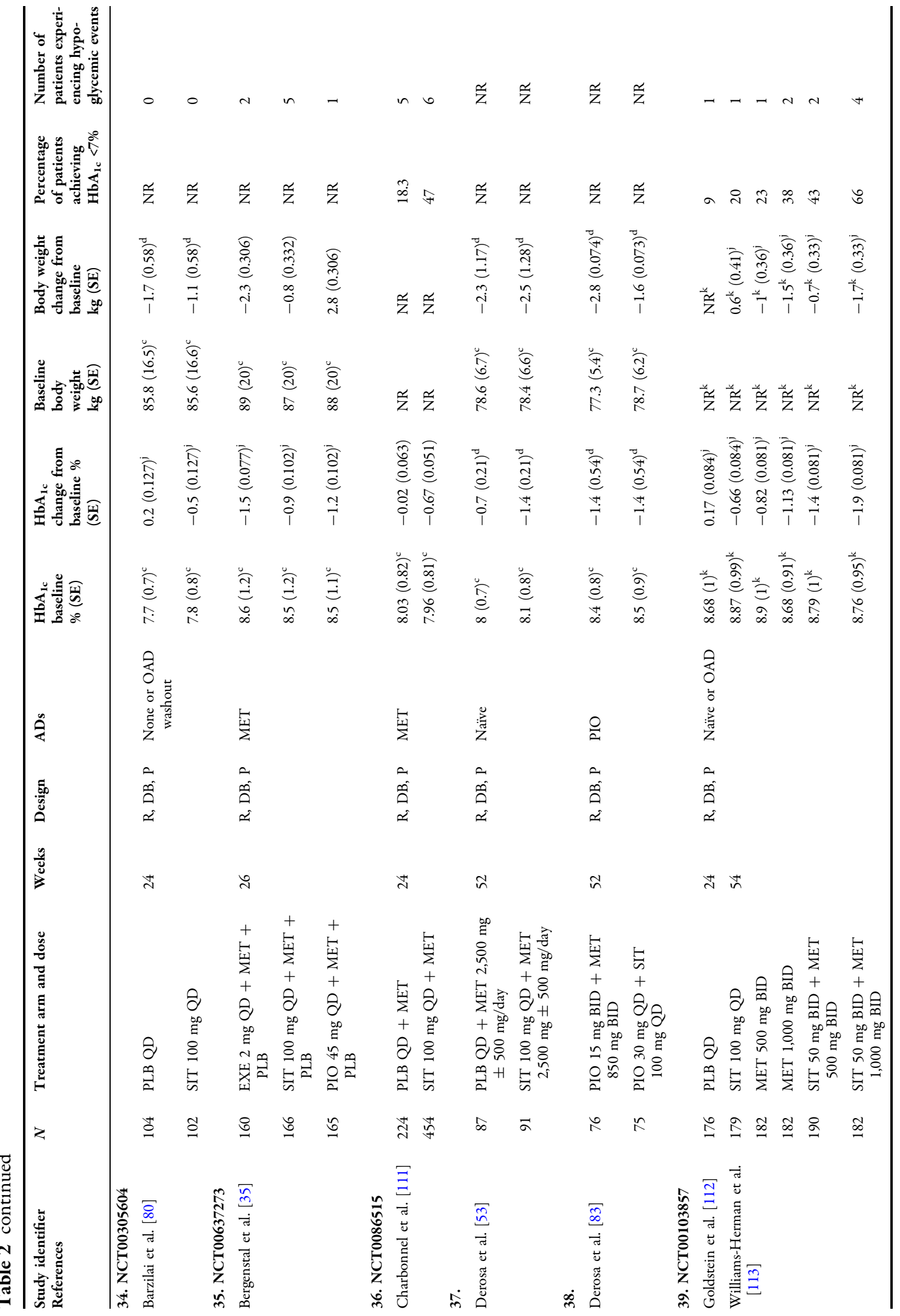




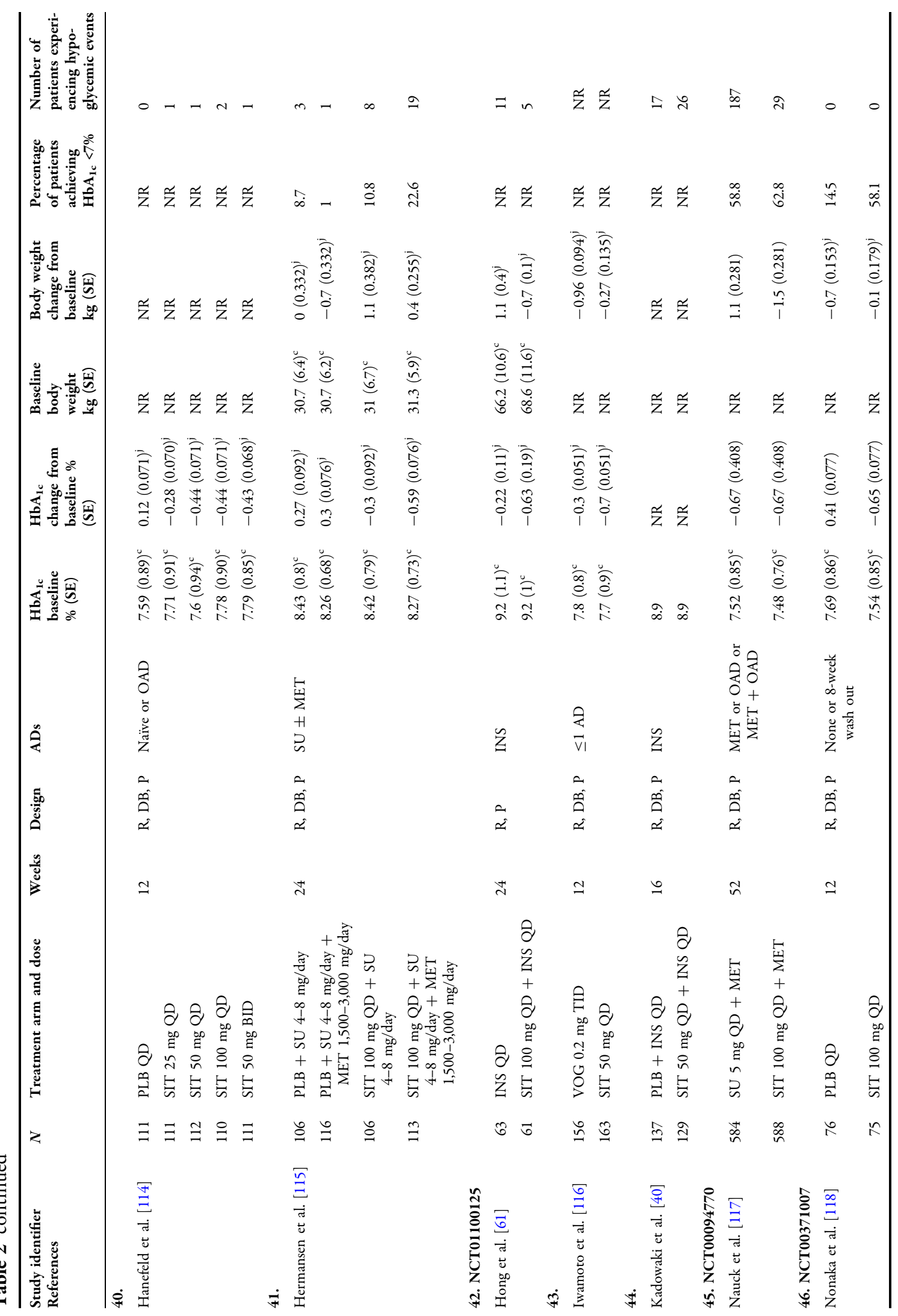




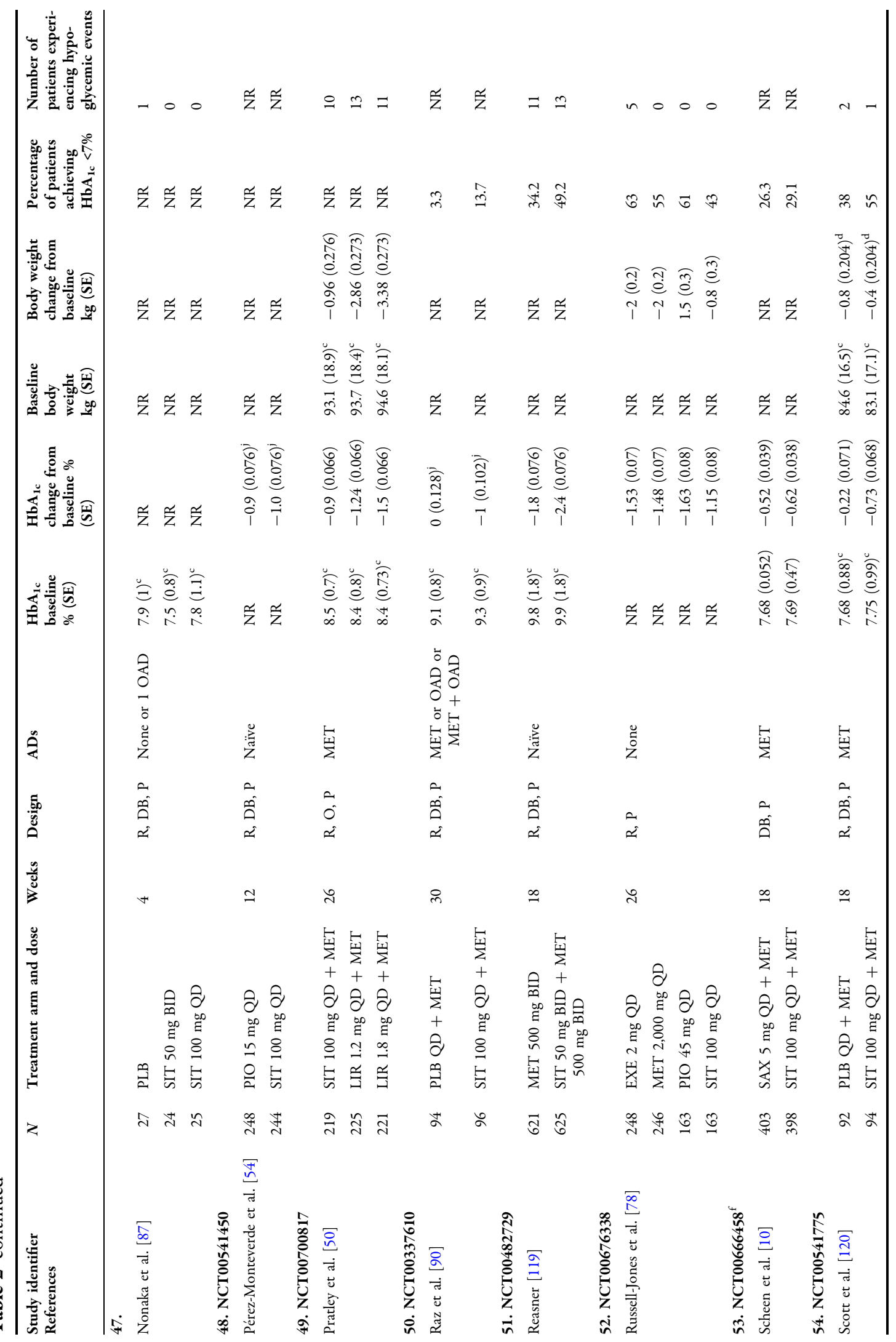




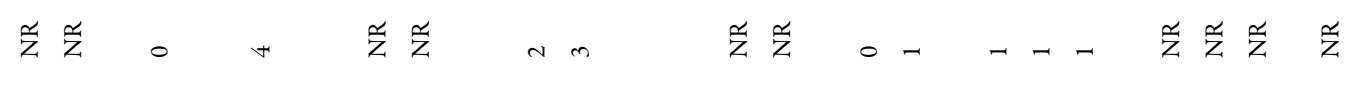

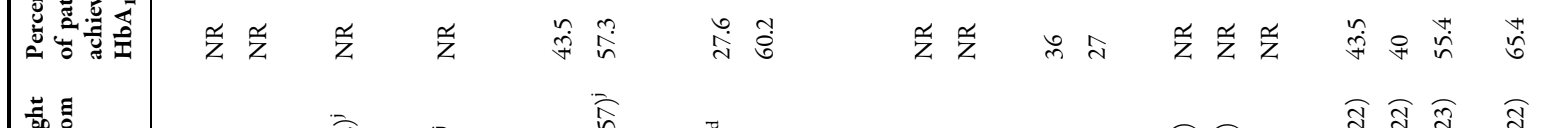

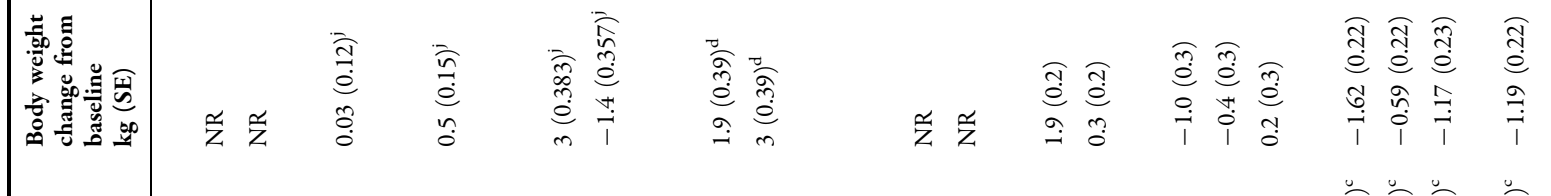

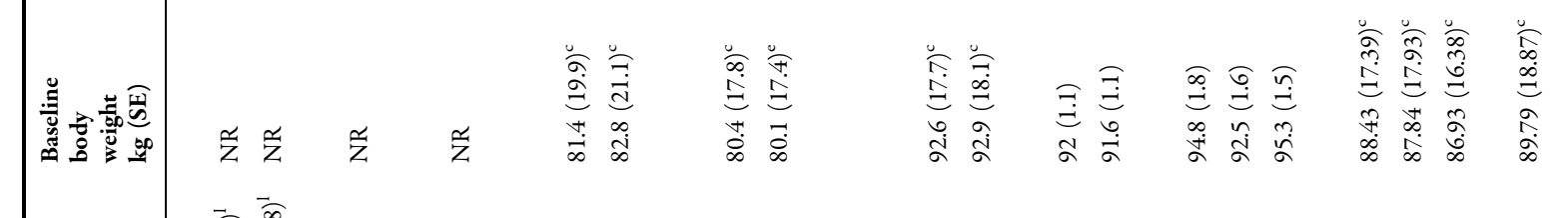

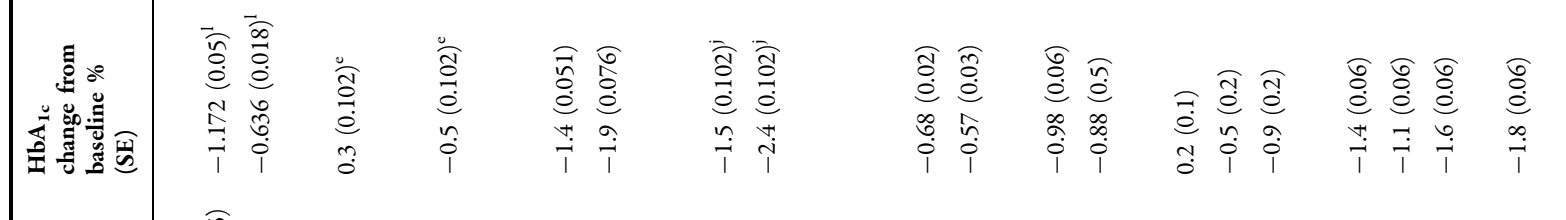

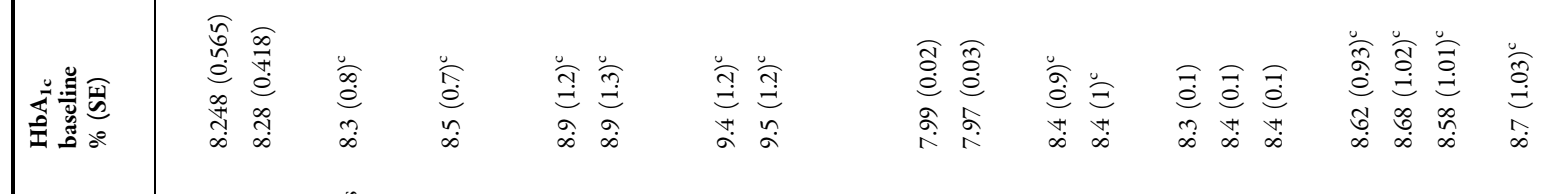

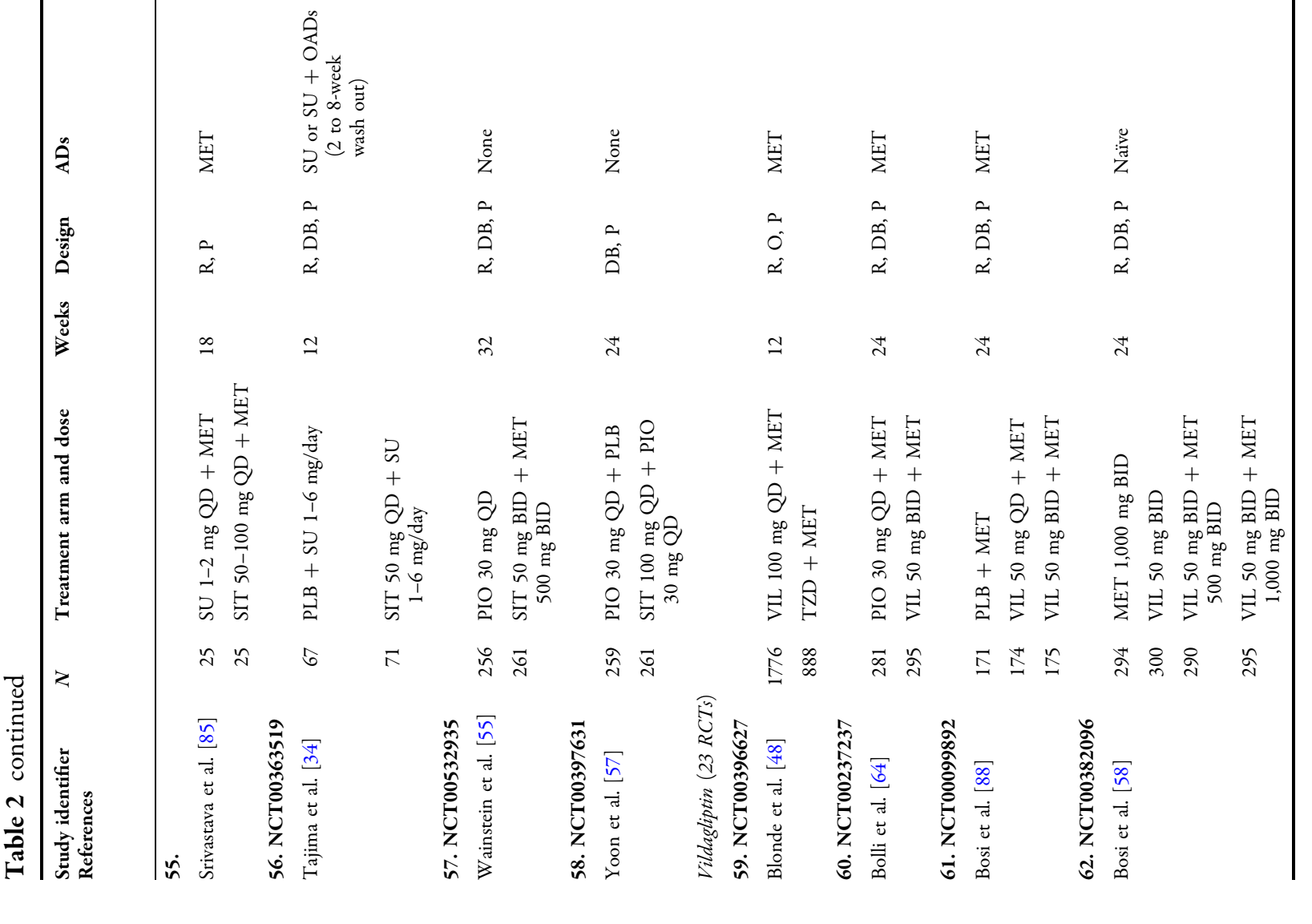




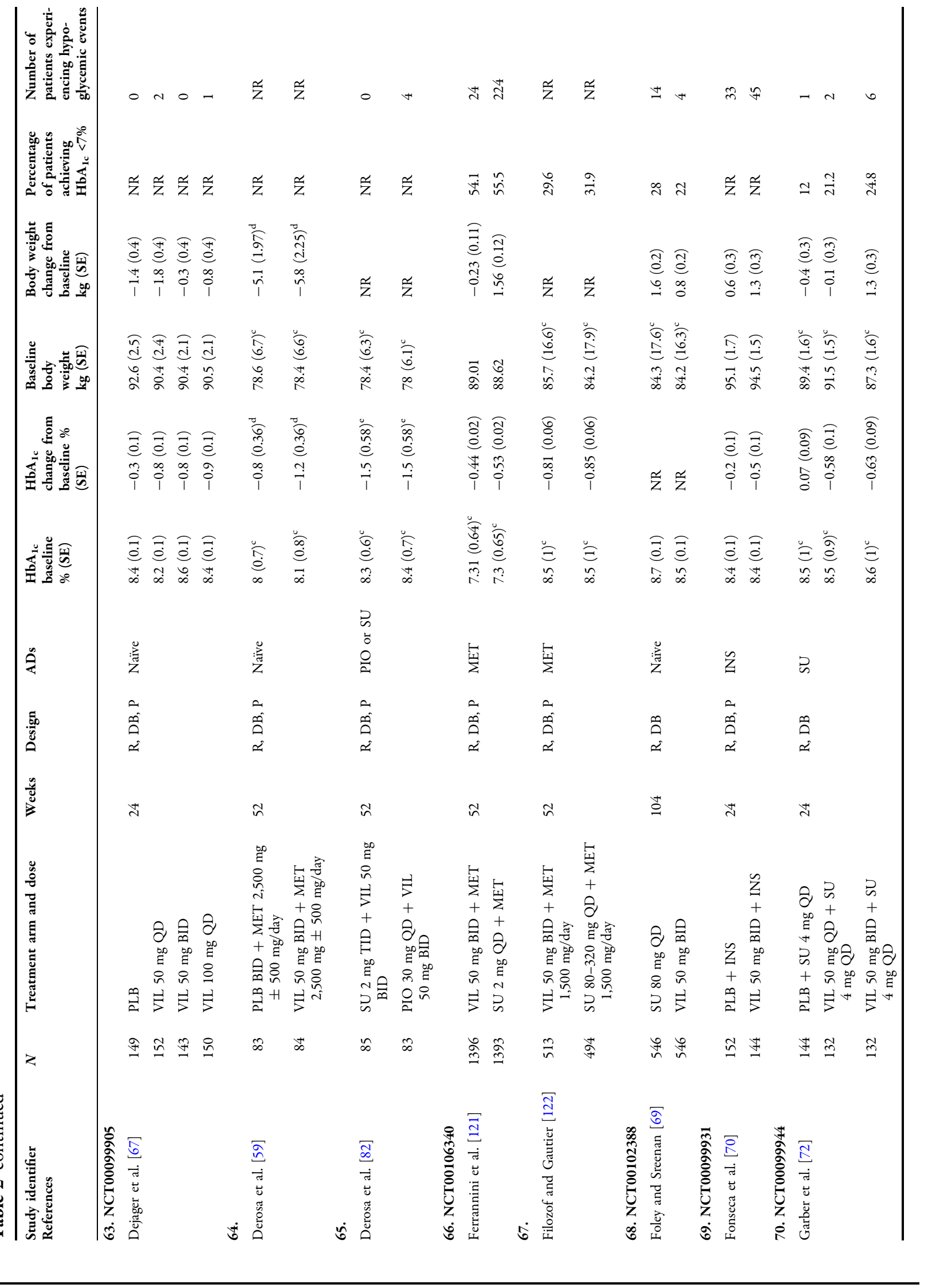




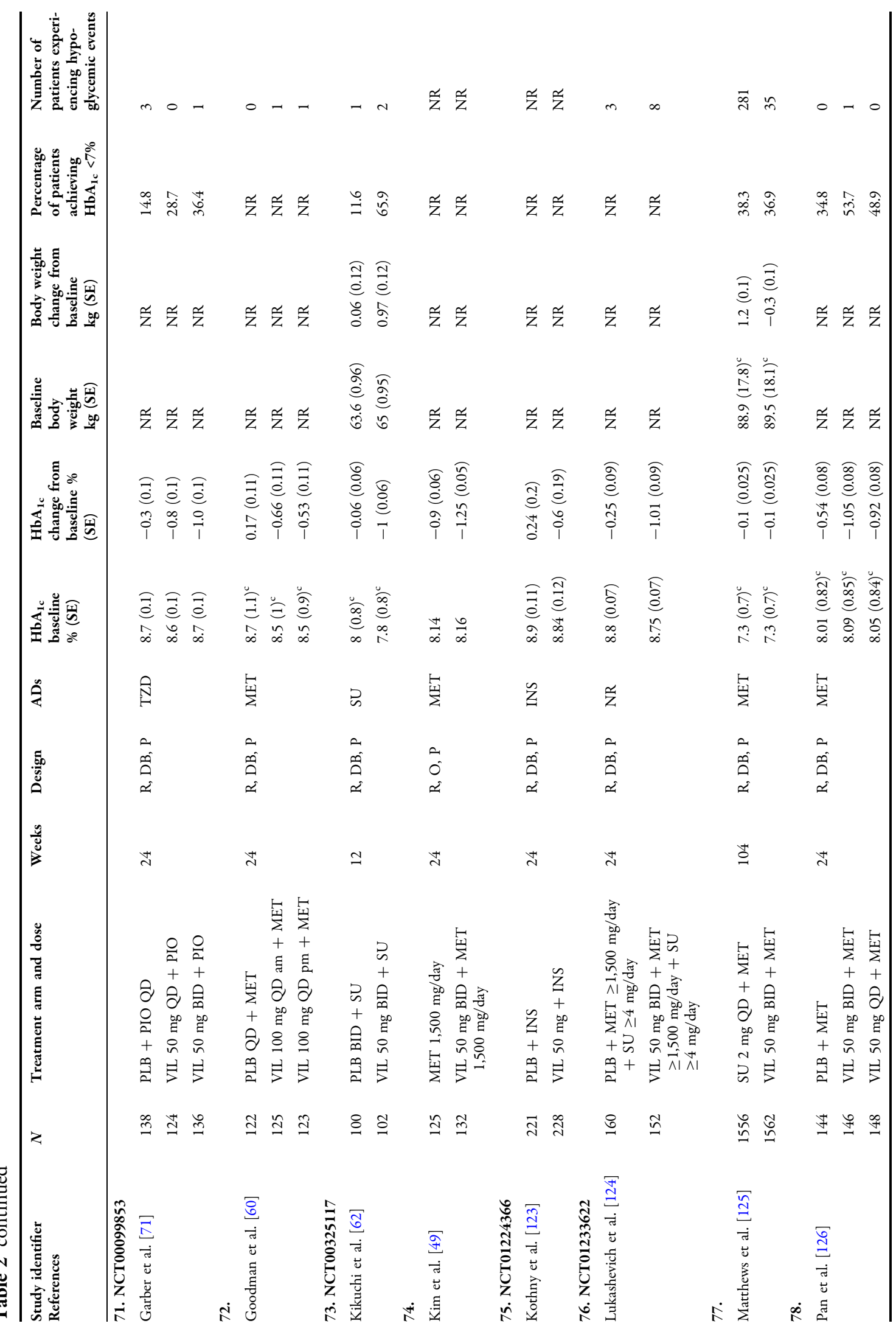




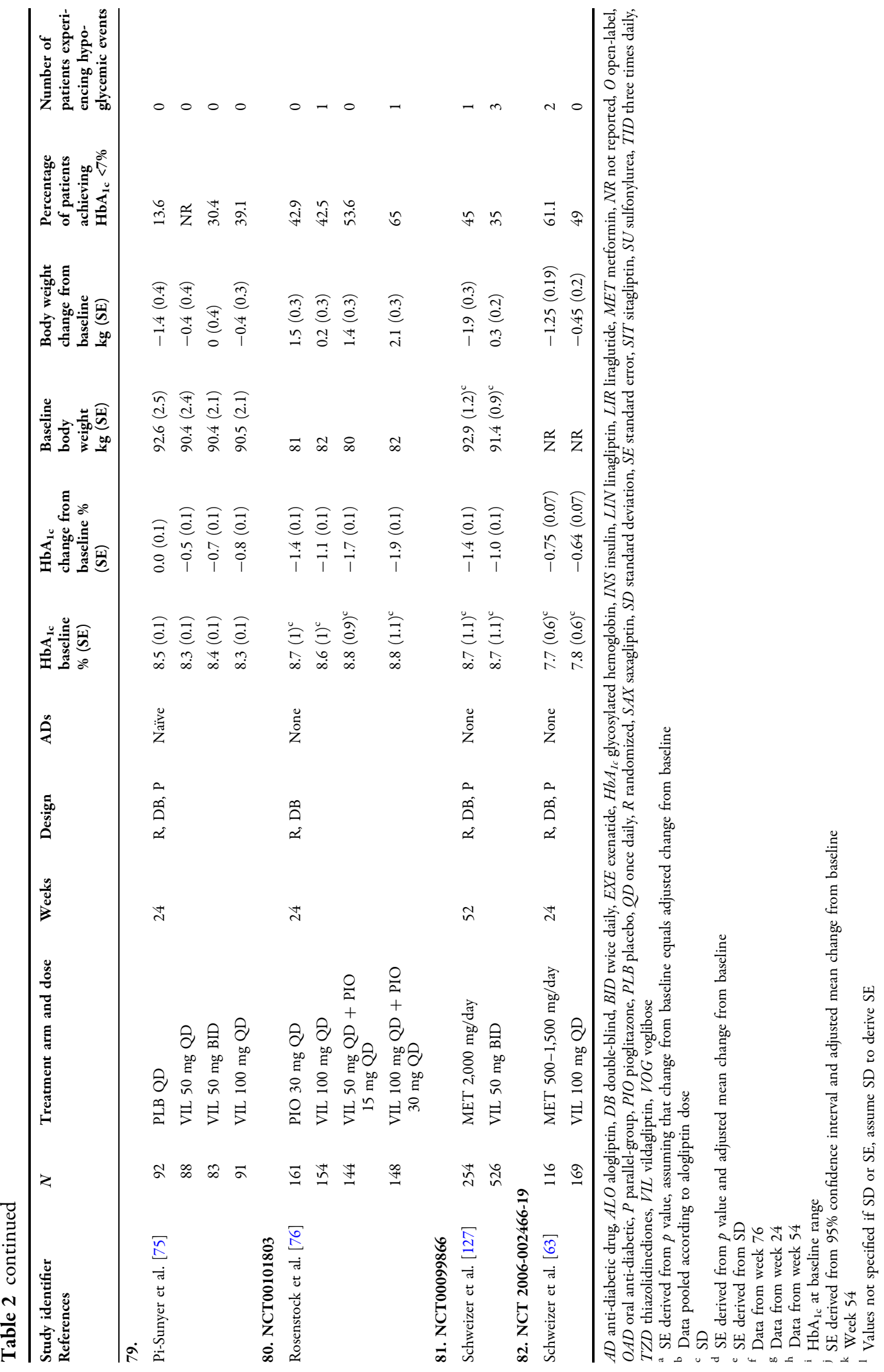




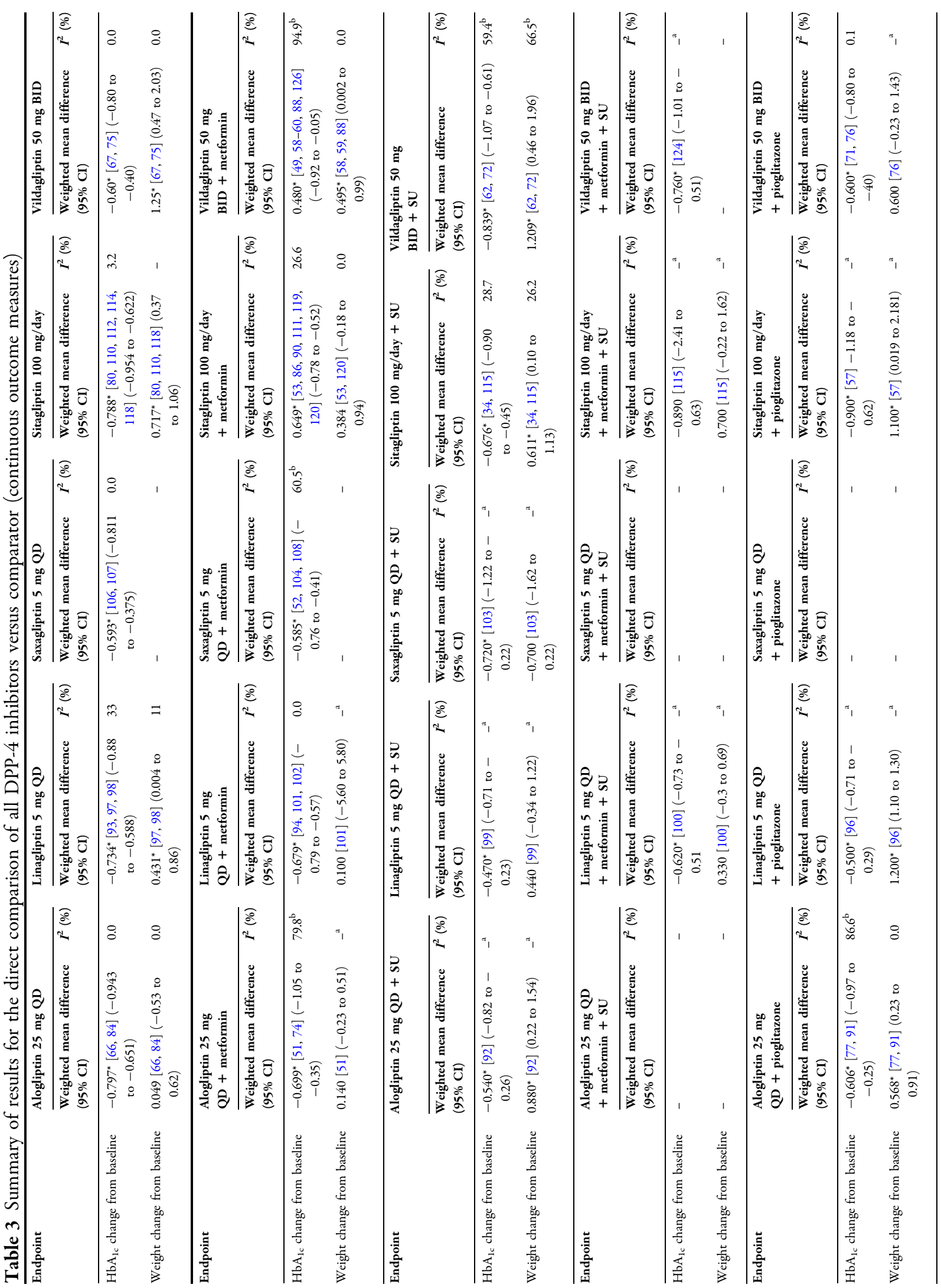




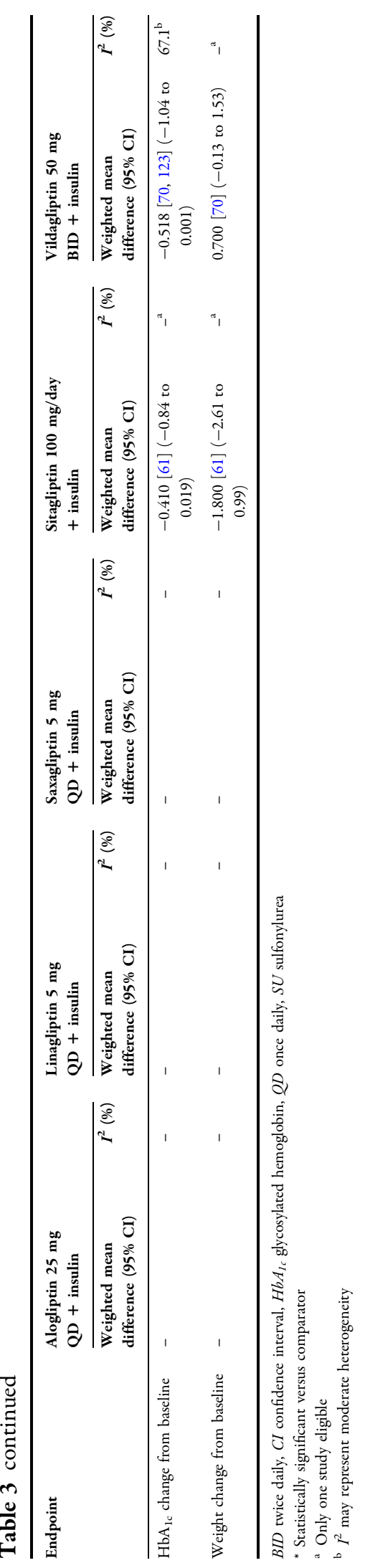

achieve $\mathrm{HbA}_{1 \mathrm{c}}<7 \%$ than those treated with placebo (Table 5). Treatment with either sitagliptin or vildagliptin resulted in a statistically significant increase in mean $(95 \%$ CI) body weight relative to placebo of $0.70 \mathrm{~kg}$ $(0.33-1.08 \mathrm{~kg})$ and $0.83 \mathrm{~kg} \quad(0.39-1.27 \mathrm{~kg})$, respectively. There was no significant difference in mean change from baseline in body weight for alogliptin or linagliptin versus placebo. Only linagliptin resulted in statistically significant lower odds of patients having a hypoglycemic event compared with placebo [OR 0.18 (95\% CI 0.0074-0.77)].

Absolute mean changes in $\mathrm{HbA}_{1 \mathrm{c}}$ from baseline to study endpoint were all reductions (i.e., improvements; Table 6); however, all reductions were non-significant. There was no significant difference between treatments in absolute mean body weight change from baseline for any DPP-4 inhibitor.

\section{DPP-4 Plus Metformin}

In the direct-comparison meta-analysis, all DPP-4 inhibitors as dual therapy with metformin were significantly more effective in achieving a greater mean reduction from baseline in $\mathrm{HbA}_{1 \mathrm{c}}$ and achieving a greater proportion of patients with $\mathrm{HbA}_{1 \mathrm{c}}$ levels $<7 \%$ compared with metformin alone (Tables 3,4 ). However, $I^{2}$ statistics $>30 \%$ may represent heterogeneity in the treatment effect of alogliptin $\left(I^{2} 79.8 \%\right)$, saxagliptin ( $I^{2}$ 60.5\%), and vildagliptin $\left(I^{2}\right.$ 94.9\%) for the $\mathrm{HbA}_{1 \mathrm{c}}$ mean change from baseline outcome, and of alogliptin $\left(I^{2} 76.5 \%\right)$, saxagliptin $\left(I^{2} 53.7 \%\right)$, and sitagliptin $\left(I^{2} 80.0 \%\right)$ for the proportion of patients achieving $\mathrm{HbA}_{1 \mathrm{c}}$ $<7 \%$.

A single head-to-head trial provided data directly comparing two DPP-4 inhibitors: sitagliptin plus metformin versus saxagliptin plus metformin [10]. The $\mathrm{HbA}_{1 \mathrm{c}}$ mean change from baseline between-group difference of 


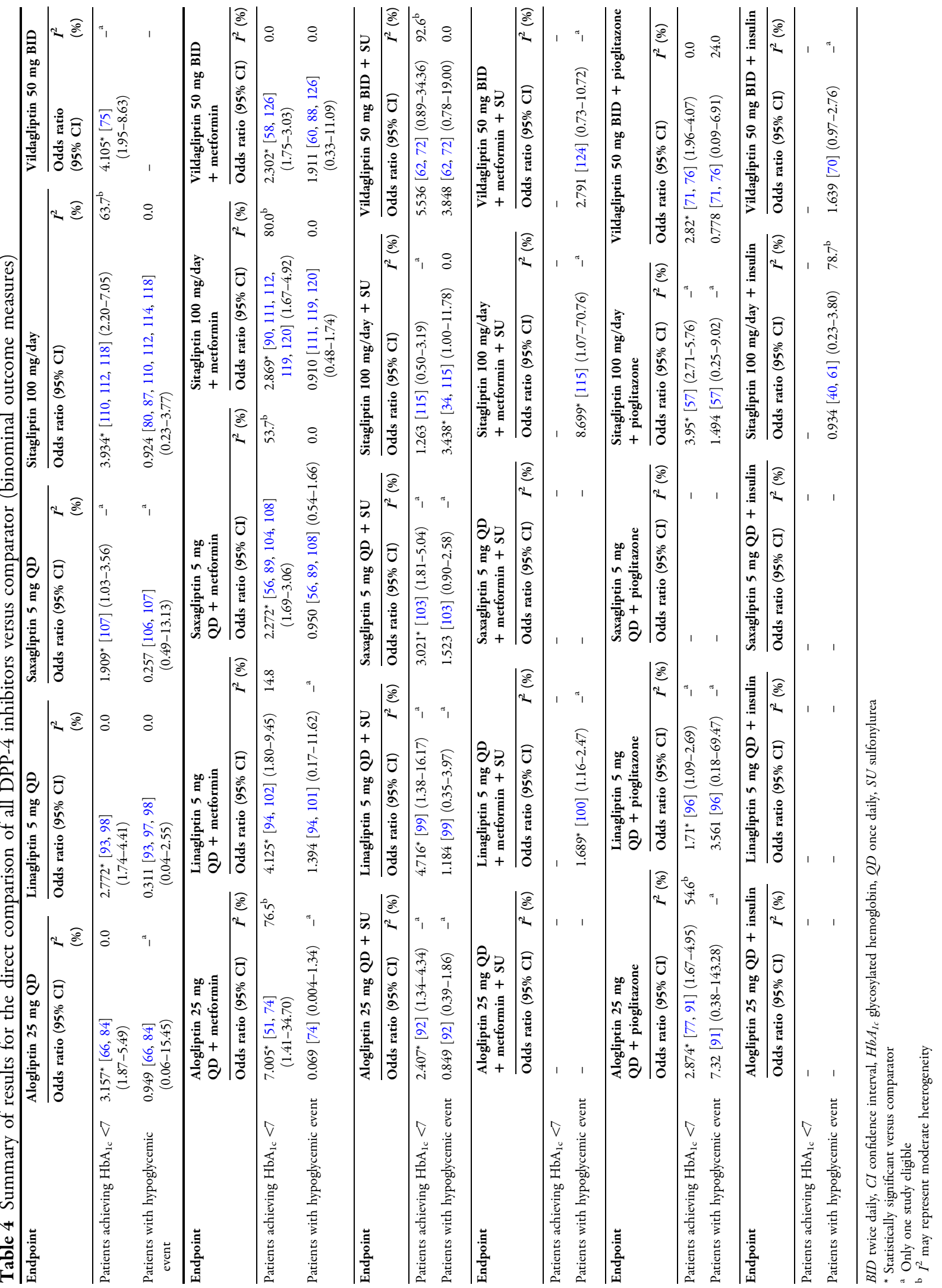




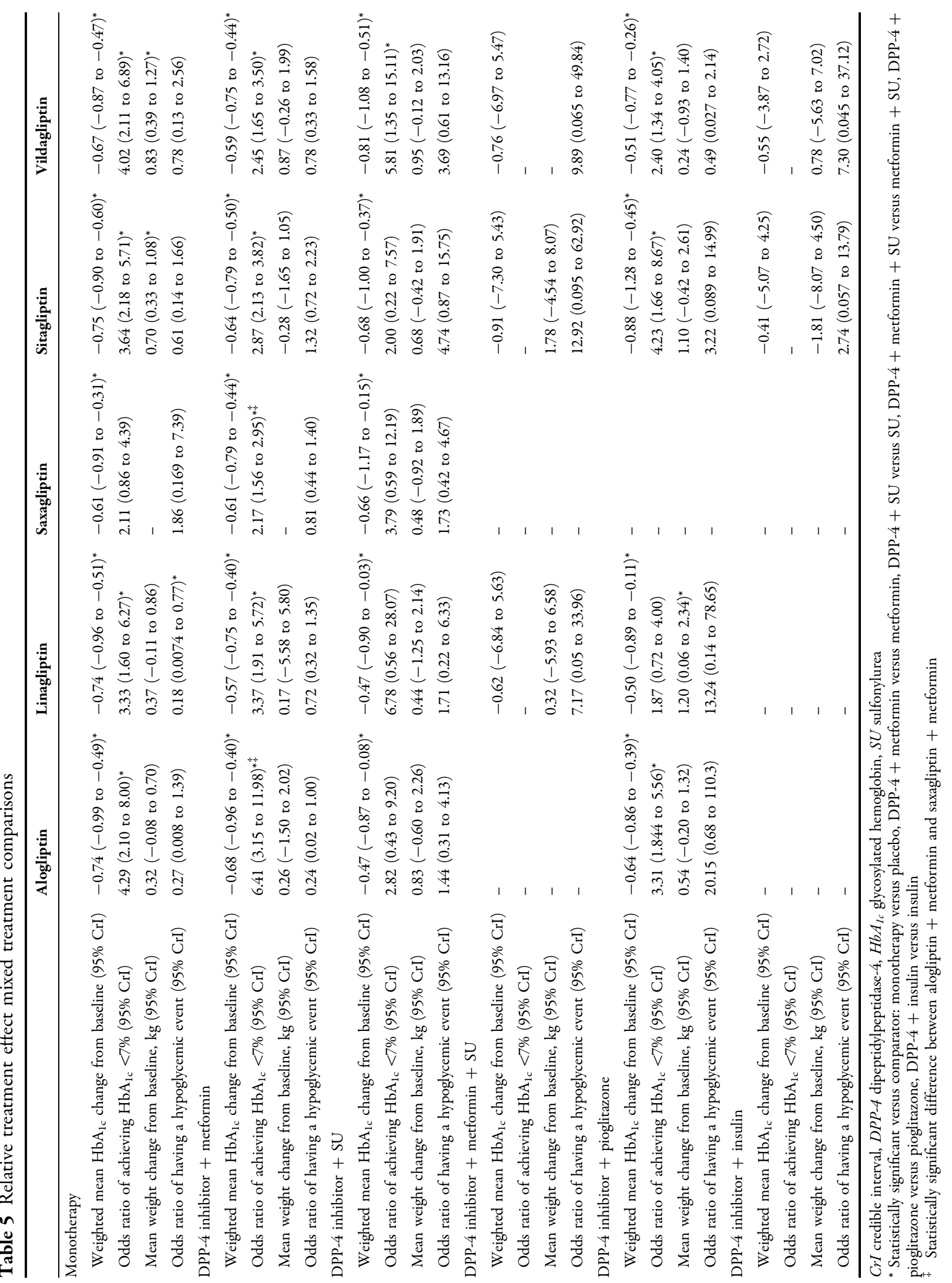




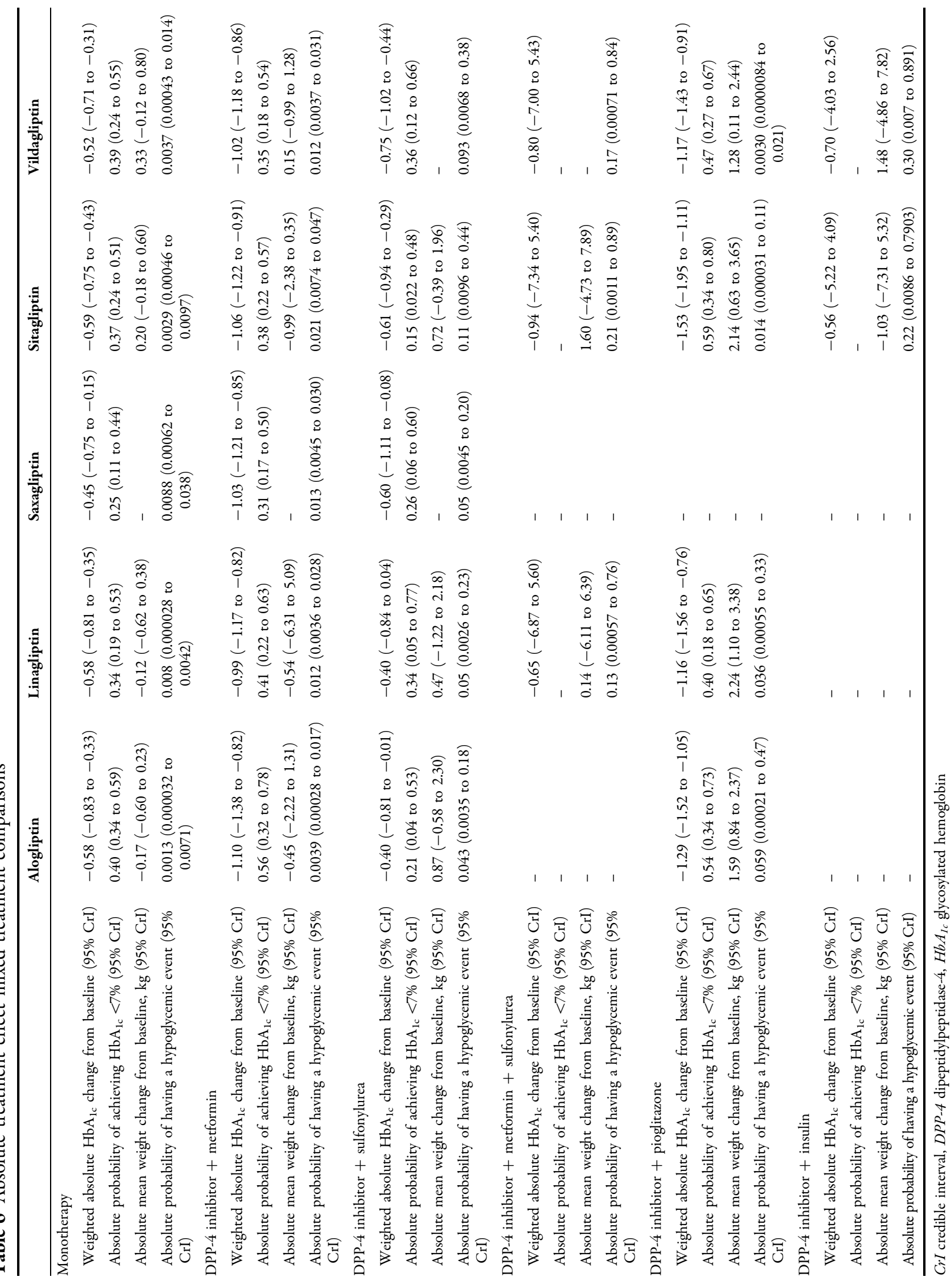


saxagliptin or sitagliptin added to stable metformin therapy was shown to be $0.09 \%$ (95\% CI -0.01 to $0.20 \%$ ), which is below the predefined criterion $(<0.3 \%)$ for non-inferiority.

The relative MTCs showed that all DPP-4 inhibitors plus metformin were significantly more effective than metformin alone in reducing mean $\mathrm{HbA}_{1 \mathrm{c}}$ from baseline and achieving a higher proportion of patients with $\mathrm{HbA}_{1 \mathrm{c}}<7 \%$ (Table 5). Patients treated with alogliptin were statistically significantly more likely to achieve $\mathrm{HbA}_{1 \mathrm{c}}<7 \%$ than patients treated with saxagliptin; however, it should be noted that the $95 \%$ credible interval for alogliptin plus metformin was very wide [OR 6.41 (3.15-11.98)]. The direct and indirect treatment effects for $\mathrm{HbA}_{1 \mathrm{c}}$ change from baseline for saxagliptin plus metformin and sitagliptin plus metformin were shown to be consistent, as assessed by Bucher's method [33], for $\mathrm{HbA}_{1 \mathrm{c}}$ mean change from baseline $(p=0.16)$, but inconsistent for the proportion of patients achieving $\mathrm{HbA}_{1 \mathrm{c}}<7 \%(p<0.05)$. There were no significant differences in mean change in body weight reported between DPP-4 plus metformin and metformin alone. No body weight data were available for saxagliptin. Absolute mean changes from baseline to study endpoint in mean $\mathrm{HbA}_{1 \mathrm{c}}$ levels were all reductions (i.e., improvements); however, none was statistically significant. Mean changes from baseline to study endpoint in body weight were also non-significant (Table 6).

\section{DPP-4 Plus Sulfonylurea}

In the direct-comparison analysis, linagliptin, saxagliptin, sitagliptin, and vildagliptin as dual therapy with SUs were significantly more effective in achieving a greater reduction in mean $\mathrm{HbA}_{1 \mathrm{c}}$ than SU alone (Tables 3, 4); however, data for linagliptin and saxagliptin were based on only one study and are inconsistent with the vildagliptin studies $\left(\mathrm{HbA}_{1 \mathrm{c}}\right.$ mean change from baseline, mean body weight change from baseline, and proportion of patients achieving $\mathrm{HbA}_{1 \mathrm{c}}<7 \%$ ( $I^{2} 59.4,66.5$, and $92.6 \%$, respectively).

In the MTCs, all DPP-4 inhibitors as dual therapy with SU were significantly more effective relative to $\mathrm{SU}$ alone in reducing $\mathrm{HbA}_{1 \mathrm{c}}$ levels (Table 5). No data were available for alogliptin plus $\mathrm{SU}$ for $\mathrm{HbA}_{1 \mathrm{c}}$ mean change from baseline. Patients receiving dual therapy were more likely to achieve $\mathrm{HbA}_{1 \mathrm{c}}<7 \%$ than those treated with SU alone; however, only the vildagliptin plus SU comparison reached statistical significance, OR $5.81 \quad(95 \% \quad$ CI 1.35-15.11).

There was no significant difference between treatments in absolute mean change from baseline to endpoint in $\mathrm{HbA}_{1 \mathrm{c}}$ or body weight for any comparison (Table 6).

\section{DPP-4 Plus Metformin Plus Sulfonylurea}

Direct-comparison data were only available for linagliptin, sitagliptin, and vildagliptin, with one study included for each; $I^{2}$ analysis was, therefore, not possible. Mean changes from baseline in $\mathrm{HbA}_{1 \mathrm{c}}$ for sitagliptin, linagliptin, and vildagliptin were $-0.890 \%$ (95\% CI -2.41 to $0.63 \%),-0.20 \%(95 \% \mathrm{CI}-0.73$ to -0.51$)$ and $-0.760 \% \quad(95 \% \quad$ CI -1.01 to $-0.51 \%)$, respectively, and mean changes in body weight for linagliptin and sitagliptin were $0.330 \mathrm{~kg} \quad(95 \% \quad \mathrm{CI} \quad-0.3$ to $0.69 \mathrm{~kg})$ and $0.700 \mathrm{~kg} \quad(95 \% \quad \mathrm{CI}-0.22$ to $1.62 \mathrm{~kg})$, respectively (Tables 3,4$)$. The proportion of patients experiencing hypoglycemic events was reported for linagliptin [OR 1.689 (95\% CI 1.16-2.47)], sitagliptin [OR 8.699 (95\% CI 1.07-70.76)], and vildagliptin [OR 2.791 (95\% CI 0.73-10.72)].

In the MTC, triple therapy with either sitagliptin, linagliptin or vildagliptin, in 
combination with metformin and SU, resulted in a non-significant relative mean reduction in $\mathrm{HbA}_{1 \mathrm{c}}$ compared with metformin plus SU. There were insufficient studies reporting the proportion of patients achieving $\mathrm{HbA}_{1 \mathrm{c}}<7 \%$ to evaluate this outcome. Neither linagliptin nor sitagliptin as triple therapy, in combination with metformin and $\mathrm{SU}$, resulted in a significant mean change from baseline in body weight (Table 5). Change from baseline in body weight was not reported for vildagliptin triple therapy.

There was no significant difference between sitagliptin, linagliptin, and vildagliptin in absolute mean change from baseline to endpoint in $\mathrm{HbA}_{1 \mathrm{c}}$. Neither linagliptin nor sitagliptin treatment combination resulted in significant changes in body weight from baseline (Table 6).

\section{DPP-4 Plus Pioglitazone}

In the direct-comparison analysis, all DPP-4 inhibitors (except saxagliptin, for which no data were available) plus pioglitazone were significantly more effective than pioglitazone alone in achieving a greater reduction in $\mathrm{HbA}_{1 \mathrm{c}}$ from baseline and achieving a greater proportion of patients with $\mathrm{HbA}_{1 \mathrm{c}}$ levels $<7 \%$ (Tables 3, 4), although the $I^{2}$ statistics for alogliptin (86.6\% and 54.6\%, respectively) may represent substantial heterogeneity.

In the MTC, all DPP-4 inhibitors as dual therapy with pioglitazone were significantly more effective relative to pioglitazone alone in reducing mean $\mathrm{HbA}_{1 \mathrm{c}}$ levels from baseline. All DPP-4 inhibitors (except linagliptin) achieved a statistically significant greater proportion of patients with $\mathrm{HbA}_{1 \mathrm{c}}$ level $<7 \%$ (Table 5). Only linagliptin plus pioglitazone resulted in a statistically significant increase in body weight compared with pioglitazone alone $(1.20 \mathrm{~kg}$; 95\% CI 0.06-2.34 kg).

There was no statistically significant difference between treatments in absolute mean change from baseline to endpoint in $\mathrm{HbA}_{1 \mathrm{c}}$ or body weight for any comparison (Table 6).

\section{DPP-4 Plus Metformin Plus Pioglitazone}

As only a single study reported data for a DPP-4 inhibitor (alogliptin) as triple therapy with metformin plus pioglitazone [65], metaanalyses were not possible. The addition of alogliptin and pioglitazone to metformin therapy was shown to result in statistically significant reductions in mean $\mathrm{HbA}_{1 \mathrm{c}}$ from baseline $(-1.4 \% \pm$ SD $0.05 \% ; p<0.001)$. When added to metformin, the triple combination therapy of alogliptin (pooled dose; 12.5 or $25 \mathrm{mg}$ ) and pioglitazone (pooled dose; 15, 30, or $45 \mathrm{mg}$ ) was shown to be statistically significantly more effective than either drug in dual therapy with metformin $(p \leq 0.001)$. Compared with pioglitazone plus metformin dual therapy, triple combination therapy with alogliptin was not associated with a statistically significant gain in body weight or increased incidence of hypoglycemic events.

\section{DPP-4 Plus Insulin}

Data were only available for sitagliptin and vildagliptin. In the direct-comparison analysis, neither sitagliptin nor vildagliptin was statistically significantly more effective than insulin alone in achieving a greater reduction in mean $\mathrm{HbA}_{1 \mathrm{c}}$ from baseline or achieving a greater proportion of patients with $\mathrm{HbA}_{1 \mathrm{c}}$ levels $<7 \%$ (Tables 3, 4). 
There was no statistically significant difference between sitagliptin or vildagliptin in the MTC of both DPP-4 inhibitors plus insulin in the relative mean change from baseline to endpoint in $\mathrm{HbA}_{1 \mathrm{c}}$. Neither of the DPP-4 inhibitors plus insulin effected a significant difference in change in mean body weight from baseline compared with insulin alone, nor statistically significant ORs of patients experiencing a hypoglycemic event (Table 5).

There was no statistically significant difference between sitagliptin and vildagliptin in absolute mean change from baseline to endpoint in $\mathrm{HbA}_{1 \mathrm{c}}$ or body weight (Table 6).

\section{DPP-4 Plus Metformin Plus Insulin}

Only one study reported data for a DPP-4 inhibitor (sitagliptin) as triple therapy with metformin and insulin [36]; meta-analyses were, therefore, not possible. The addition of sitagliptin to insulin plus metformin resulted in a statistically significantly greater mean reduction in $\mathrm{HbA}_{1 \mathrm{c}}$ from baseline $(-1.49 \%$; $p<0.05)$ and a greater proportion of patients achieving $\mathrm{HbA}_{1 \mathrm{c}}<7 \%$ (88\%; $\left.p<0.05\right)$ versus metformin plus insulin. A statistically nonsignificant increase in body weight was observed $\quad(0.1 \pm \mathrm{SD} \quad 1.6 \mathrm{~kg}) \quad$ with triple combination therapy of sitagliptin plus insulin and metformin versus metformin plus insulin.

\section{Sensitivity Analyses}

Sensitivity analyses were conducted to assess the robustness of the conclusions drawn from the base-case estimates. As the Cochrane Collaboration considers $I^{2}>30 \%$ to represent moderate heterogeneity in the effect estimate, analyses breaching this threshold were examined. Appendix 5 (Electronic Supplementary Material) shows directcomparison meta-analyses with $I^{2}>30 \%$.
Study references highlighted in bold were identified as outliers in the forest plots (data not shown) of these analyses, suggesting that these studies may be a major cause of inconsistency in the effect estimate. Two studies were identified as outliers for $\mathrm{HbA}_{1 \mathrm{c}}$ mean change from baseline $[88,89]$ and two were identified for proportion of patients achieving $\mathrm{HbA}_{1 \mathrm{c}}<7 \%[89,90]$.

Sensitivity analyses were performed by investigating the effect of removing these outliers from the respective direct-comparison analyses. No further action was possible for analyses in which there were only two studies, as it was not possible to identify which study was likely to represent a 'true' estimate of the effect. Heterogeneity in the $\mathrm{HbA}_{1 \mathrm{c}}$ mean change from baseline analysis for linagliptin versus placebo was not examined as the $I^{2}$ statistic was borderline at $33 \%$ and there was no obvious outlier in the forest plot.

Table 7 summarizes the new $I^{2}$ values from studies that remained in the direct-comparison meta-analysis for each outcome when outlying studies had been removed. These studies all compared a DPP-4 inhibitor plus metformin versus metformin alone and removing them reduced inconsistency in the treatment effect. The $I^{2}$ values for mean $\mathrm{HbA}_{1 \mathrm{c}}$ change from baseline in the saxagliptin plus metformin versus metformin and sitagliptin plus metformin versus metformin comparisons decreased by $60.5 \%$ and $30.3 \%$, respectively. For the $\mathrm{HbA}_{1 \mathrm{c}}<7 \%$ outcome, the $I^{2}$ value for the sitagliptin plus metformin versus metformin comparison decreased by $80 \%$ when DeFronzo et al. [89] was removed. Raz et al. [90] was also highlighted as a possible outlier responsible for the inflated $I^{2}$ value for the direct-comparison meta-analysis of sitagliptin plus metformin versus metformin. However, when this study was removed, the $I^{2}$ value increased by $9.2 \%$ so 


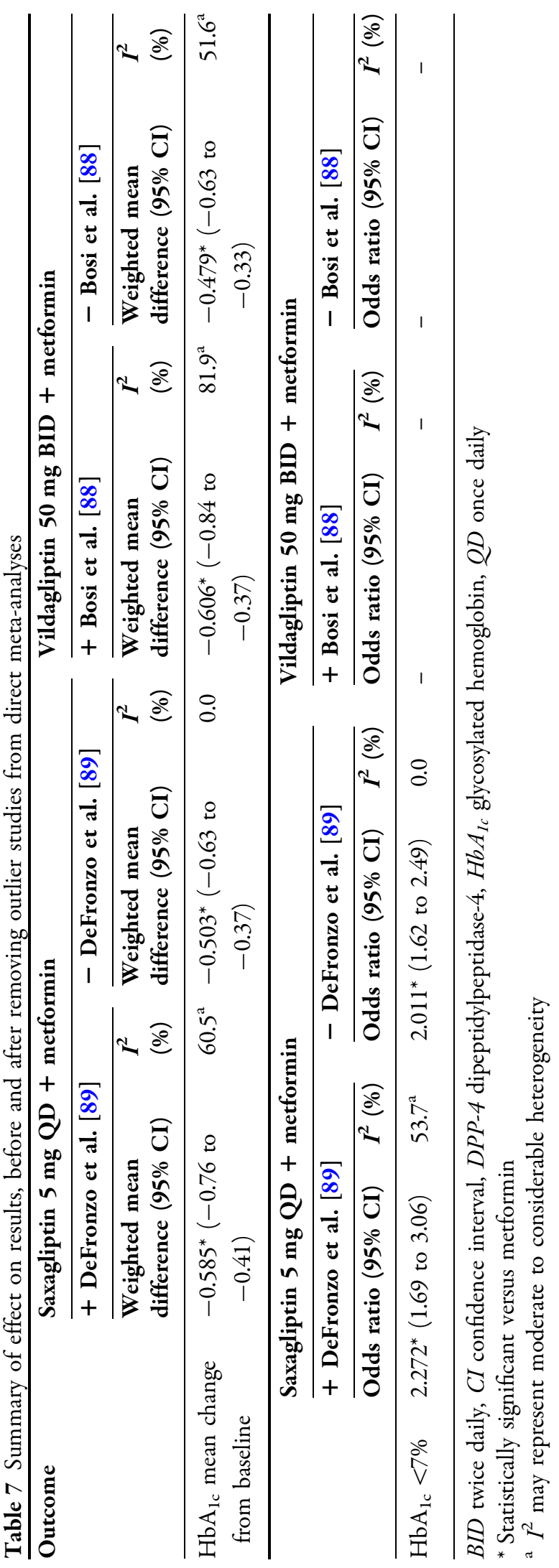

the study was re-introduced into the model for the MTC.

Table 7 reports how direct-comparison metaanalysis effect sizes changed in sensitivity analyses in which the DeFronzo et al. [89] and Bosi et al. [88] studies were removed from the analysis.

Although the removal of studies that were highlighted as outliers in direct meta-analyses reduced $I^{2}$ values, average effect sizes and direction of effect remained largely unchanged. CIs narrowed, indicating greater consistency in the effect estimate.

Following this, relative MTCs were re-run for both the $\mathrm{HbA}_{1 \mathrm{c}}$ change from baseline and $\mathrm{HbA}_{1 \mathrm{c}}$ $<7 \%$ networks (Table 8). The removal of DeFronzo et al. [89] and Bosi et al. [88] resulted in a small reduction in the effect estimate for weighted mean change in $\mathrm{HbA}_{1 \mathrm{c}}$ from baseline with vildagliptin plus metformin; however, this change did not affect the noninferiority conclusion for all DPP-4 plus metformin therapies. Similarly, there were also small reductions for linagliptin plus metformin and sitagliptin plus metformin for the OR of patients achieving $\mathrm{HbA}_{1 \mathrm{c}}<7 \%$. Similar to $\mathrm{HbA}_{1 \mathrm{c}}$ mean change from baseline, effect estimates for proportion of patients achieving $\mathrm{HbA}_{1 \mathrm{c}}<7 \%$ remained largely unchanged. A small reduction in the effect estimate for saxagliptin plus metformin versus metformin was recorded; however, this did not change the findings from the base-case MTC. Patients treated with alogliptin were still statistically significantly more likely to achieve $\mathrm{HbA}_{1 \mathrm{c}}<7 \%$ than those treated with saxagliptin; however, it should be noted that the $95 \%$ credible interval for alogliptin plus metformin is very wide [OR 6.39 (3.19-11.85)].

Therefore, the impact of removing studies with heterogeneity, as identified by the $I^{2}$ statistic in direct-comparison meta-analyses, had little or no impact on the overall 


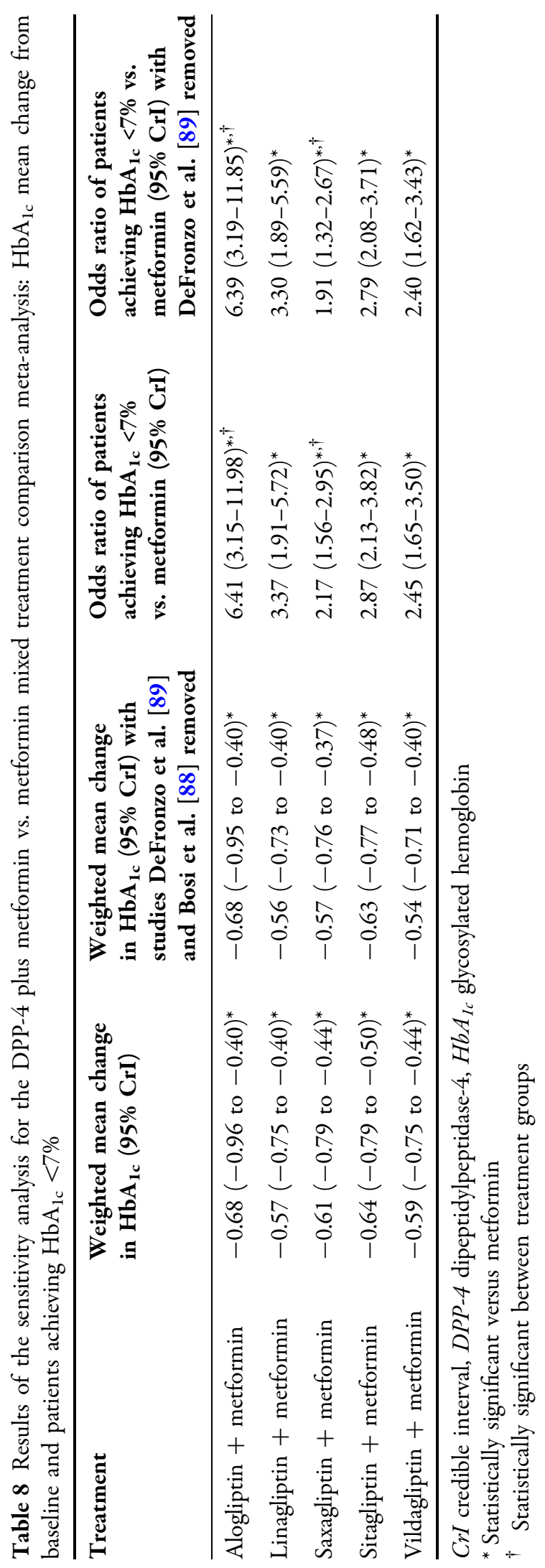

conclusions drawn from the MTC analysis comparing $\mathrm{HbA}_{1 \mathrm{c}}$ mean reduction from baseline and proportion of patients achieving $\mathrm{HbA}_{1 \mathrm{c}}$ target $<7 \%$ between DPP-4 inhibitors.

\section{DISCUSSION}

\section{Principal Findings}

The principal finding of this systematic review and MTC of the DPP-4 inhibitors is the demonstration of equivalent effects across the class in terms of key efficacy and safety outcomes $\left(\mathrm{HbA}_{1 \mathrm{c}}\right.$ mean change from baseline, proportion of patients achieving $\mathrm{HbA}_{1 \mathrm{c}}<7 \%$, mean change in body weight from baseline, and number of patients with hypoglycemic events between: alogliptin, linagliptin, saxagliptin, sitagliptin, and vildagliptin as monotherapy or dual therapy (plus metformin or SU); alogliptin, linagliptin, sitagliptin and vildagliptin as dual therapy (plus pioglitazone); sitagliptin and vildagliptin as dual therapy (plus insulin); or linagliptin, sitagliptin and vildagliptin as triple therapy (plus metformin and SU), in patients with type 2 diabetes whose glucose levels were insufficiently controlled. The only treatment comparison for which there was a statistically significant difference in the treatment effect was in patients on alogliptin plus metformin, who achieved $\mathrm{HbA}_{1 \mathrm{c}}<7 \%$ more frequently than those treated with saxagliptin plus metformin [OR 6.41 (95\% CI 3.15-11.98) versus 2.17 (95\% CI 1.56-2.95)]; however, it should be noted that the $95 \%$ credible interval for alogliptin plus metformin is very wide.

In the direct-comparison meta-analyses, the majority of DPP-4 inhibitors, either as monotherapy or as dual or triple therapy, were significantly more effective than the respective comparator in reducing mean $\mathrm{HbA}_{1 \mathrm{c}}$ (i.e., improving glycemic control). The exceptions were sitagliptin in combination with metformin 
plus SU versus metformin plus $\mathrm{SU}$, and sitagliptin or vildagliptin plus insulin versus insulin alone. Although the $I^{2}$ statistic indicated moderate to substantial heterogeneity in the effect estimate and subsequent removal of outliers resulted in a reduction in the corresponding $I^{2}$ statistic, the average effect sizes and the direction of effect remained largely unchanged. Therefore, the removal of studies with heterogeneity had little or no impact on the overall conclusions drawn from the MTCs comparing mean change from baseline in $\mathrm{HbA}_{1 \mathrm{c}}$ and proportion of patients achieving $\quad \mathrm{HbA}_{1 \mathrm{c}} \quad<7 \%$ between DPP-4 inhibitors.

The results from the MTC analyses and direct-comparison meta-analyses of the DPP-4 inhibitors in this paper are in line with previously published articles by Scheen [2] and Esposito et al. [5]. Similar to the review of DPP-4 inhibitors by Scheen [2] and the meta-analyses reported by Esposito et al. [5], the results of the MTC indicate no differences between the DPP-4 inhibitors, using predefined criteria of overlapping 95\% credible intervals. This was the case for DPP-4 inhibitors that were used either as monotherapy or as dual or triple therapy in combination with other antidiabetic treatments (including metformin, SU, pioglitazone, or insulin). However, the current analysis expanded on that previously published by Esposito et al. [5]. In addition to individual indirect-comparison meta-analyses of DPP-4 inhibitors, we also conducted MTCs of all DPP-4 inhibitors, including linagliptin (previously not included by Esposito et al. [5]), for the same four outcomes.

Separate MTCs were conducted for DPP-4 inhibitors as monotherapy versus placebo or as dual- or triple-therapy combinations versus the respective monotherapy or dual-therapy comparator, as appropriate. Previous analyses pooled studies of DPP-4 inhibitors versus placebo and studies of DPP-4 inhibitor combination therapy versus other anti-diabetic combinations [5]. Esposito et al. [5] excluded studies with a randomized duration of $<12$ weeks; this current review did not exclude studies based upon duration (randomized study durations ranged from 4 weeks to 104 weeks). Despite these differences, the current study reached the same conclusion of no difference between all DPP-4 inhibitors across the four outcomes analyzed.

\section{Strengths and Weaknesses of the Study}

The strength of this analysis is its robust and transparent design. We conducted a systematic search and rigorous review of published RCTs of pharmacologic treatments in patients with type 2 diabetes and inadequate glycemic control, according to predefined criteria. Further studies, often unpublished, were identified by reviewing the reference lists of selected published systematic reviews and meta-analyses. Data extracted from included studies of DPP-4 inhibitors were analyzed using robust statistical methodology. Both direct- and indirect-comparison data were combined in an MTC using a Bayesian approach. The Bayesian approach combines data in a robust and more intuitive way than a standard frequentist approach.

The comparison of the DPP-4 inhibitors was limited to four outcomes $\left(\mathrm{HbA}_{1 \mathrm{c}}\right.$ mean change from baseline, proportion of patients achieving $\mathrm{HbA}_{1 \mathrm{c}}<7 \%$, mean change in body weight from baseline, and number of patients experiencing a hypoglycemic event).

Studies from which data were extracted were assessed to establish if they represented a robust source of information. A potential weakness of the studies included in the statistical analyses 
was identified: the majority of studies were deemed to have between one and three 'unclear' assessments out of the seven assessment criteria. If the assessments were deemed to be 'unclear', it was not possible to differentiate between studies that had been poorly reported, and studies that were poorly conducted (i.e., of low quality, making it difficult to assess the quality/level of bias in the majority of the studies included in the analysis). Ten studies eligible for data extraction were deemed to be of low quality and, therefore, at a high risk of bias. However, only one of these was eventually included in the statistical analyses, the remainder being excluded for other reasons.

Further, owing to the addition of a MESH/ Embase 'Drug Therapy' term restriction in the search string, it is possible that studies not indexed as drug therapy could have been overlooked. However, without this search term, the review would have been unmanageable in terms of the number of titles/abstracts to be filtered. Furthermore, unpublished data were not specifically sought, despite a structured search strategy to identify published articles and unpublished studies from a selection of published systematic reviews and meta-analyses. It thus remains possible that some unpublished studies were not identified.

The MTCs were also limited by a number of factors. In order to have sufficient studies to allow quantitative analysis, assumptions were made regarding the imputation of missing standard errors and to include data for all DPP-4 inhibitor and comparator doses reported in all eligible studies identified. In addition, studies of the various SUs were pooled. Variability in the efficacy of treatment doses and/or different SUs is a possible source of heterogeneity and hence a limitation of the analyses. Furthermore, small study numbers remained in some networks, which may have resulted in uncertain estimated treatment effects. Extension-phase data were excluded, as most studies were no longer randomized and the study population size was generally limited.

Finally, heterogeneity $\left(I^{2}<30 \%\right)$ in the treatment effect between studies included in the direct-comparison meta-analyses was also identified for a number of treatment comparisons. Although sensitivity analyses were conducted, where appropriate, to confirm the robustness of the base-case analyses, heterogeneity in the effect estimates represents some uncertainty in the overall treatment effect.

\section{Conclusion and Further Research}

This systematic review and MTC of DPP-4 inhibitors confirmed no difference between alogliptin, linagliptin, saxagliptin, sitagliptin, and vildagliptin, either as monotherapy, or as dual therapy (plus metformin or SU); alogliptin, linagliptin, sitagliptin, and vildagliptin as dual therapy (plus pioglitazone); sitagliptin and vildagliptin as dual therapy (plus insulin), or linagliptin, sitagliptin, and vildagliptin as triple therapy (plus metformin and SU). The study showed that the DPP-4 inhibitors have similar efficacy in terms of mean reduction (i.e., improvement) in $\mathrm{HbA}_{1 \mathrm{c}}$ from baseline, increased proportion of patients achieving $\mathrm{HbA}_{1 \mathrm{c}}<7 \%$, mean change in body weight from baseline, and number of patients experiencing a hypoglycemic event. Further research is required to assess the long-term safety and efficacy of this class of oral anti-diabetic agents. The current MTCs excluded extension-phase data.

\section{ACKNOWLEDGMENTS}

This study was funded by Takeda Pharmaceuticals International GmbH, Zurich, 
Switzerland. All named authors meet the ICMJE criteria for authorship for this manuscript, take responsibility for the integrity of the work as a whole, and have given final approval for the version to be published.

Paul Craddy and K. Ian Johnson were involved in determining the scope and research question for the systematic review and performed critical review of the manuscript. Hannah-Jayne Palin was involved in screening of articles and dataextraction stages of the systematic review and was responsible for all stages of manuscript preparation.

Claire Chadwick and Gillian Sibbring are employees of McCann Complete Medical (Macclesfield, UK), which was commissioned by Takeda Pharmaceuticals International GmbH to conduct the systematic review and metaanalysis. Claire Chadwick undertook project management of the systematic review and meta-analysis and was also involved in finalizing the scope of the analyses, first- and second-pass screening of articles, and dataextraction stages of the systematic review. Gillian Sibbring was involved in data checking for statistical analyses and also undertook project management and critical review of manuscript at all stages of preparation. Daniel Shaw was an employee of McCann Complete Medical at the time the study was undertaken and performed all statistical analyses.

Conflict of interest. Hannah-Jayne Palin was an employee of McCann Complete Medical at the time the study was undertaken, a company sponsored by Takeda Pharmaceuticals International $\mathrm{GmbH}$ to conduct this study and prepare the manuscript. K. Ian Johnson was an employee of McCann Complete Medical at the time the study was undertaken, a company sponsored by Takeda Pharmaceuticals
International $\mathrm{GmbH}$ to conduct this study and prepare the manuscript. Paul Craddy was an employee of Takeda Pharmaceuticals International $\mathrm{GmbH}$ at the time the study was undertaken.

Compliance with ethics guidelines. The analysis in this article is based on previously conducted studies and does not involve any new studies of human or animal subjects performed by any of the authors.

Open Access. This article is distributed under the terms of the Creative Commons Attribution Noncommercial License which permits any noncommercial use, distribution, and reproduction in any medium, provided the original author(s) and the source are credited.

\section{REFERENCES}

1. Krentz AJ, Patel MB, Bailey CJ. New drugs for type 2 diabetes mellitus: what is their place in therapy? Drugs. 2008;68(15):2131-62.

2. Scheen AJ. A review of gliptins in 2011. Expert Opin Pharmacother. 2012;13(1):81-99.

3. Phung OJ, Scholle JM, Talwar M, Coleman CI. Effect of noninsulin antidiabetic drugs added to metformin therapy on glycemic control, weight gain, and hypoglycemia in type 2 diabetes. JAMA. 2010;303(14):1410-8.

4. Baetta R, Corsini A. Pharmacology of dipeptidyl peptidase-4 inhibitors: similarities and differences. Drugs. 2011;71(11):1441-67.

5. Esposito K, Cozzolino D, Bellastella G, et al. Dipeptidyl peptidase-4 inhibitors and HbA1c target of $<7 \%$ in type 2 diabetes: meta-analysis of randomized controlled trials. Diabetes Obes Metab. 2011;13(7):594-603.

6. Fakhoury WK, Lereun C, Wright D. A meta-analysis of placebo-controlled clinical trials assessing the efficacy and safety of incretin-based medications in patients with type 2 diabetes. Pharmacology. 2010;86(1):44-57. 
7. Monami M, Iacomelli I, Marchionni N, Mannucci E. Dipeptidyl peptidase- 4 inhibitors in type 2 diabetes: a meta-analysis of randomized clinical trials. Nutr Metab Cardiovasc Dis. 2010;20(4):224-35.

8. Neumiller JJ, Wood L, Campbell RK. Dipeptidyl peptidase- 4 inhibitors for the treatment of type 2 diabetes mellitus. Pharmacotherapy. 2010;30(5):463-84.

9. Scheen AJ. Cytochrome P450-mediated cardiovascular drug interactions. Expert Opin Drug Metab Toxicol. 2011;7(9):1065-82.

10. Scheen AJ, Charpentier G, Ostgren CJ, Hellqvist A, Gause-Nilsson I. Efficacy and safety of saxagliptin in combination with metformin compared with sitagliptin in combination with metformin in adult patients with type 2 diabetes mellitus. Diabetes Metab Res Rev. 2010;26(7):540-9.

11. Liberati A, Altman DG, Tetzlaff J, et al. The PRISMA statement for reporting systematic reviews and meta-analyses of studies that evaluate healthcare interventions: explanation and elaboration. BMJ. 2009;339:b2700.

12. Proquest Dialog. http://search.proquest.com/ (Accessed Nov 30, 2012).

13. EBSCO. http://www.ebscohost.com/ (Accessed Nov $30,2012)$.

14. NHS Economic Evaluation Database (NHS EED). http://www.crd.york.ac.uk/crdweb/Homepage.asp (Accessed Nov 30, 2012).

15. Health Economic Evaluations Database. http:// heed.onlinelibrary.wiley.com/heed/ohe/CnIsapi.dll? fld $=X \&$ alias=OHE\&uni $=58187 \&$ SetUserType $=1 \&$ jump $=$ Search\&type $=4 \&$ Browser $=$ MSIE (Accessed Nov 30, 2012).

16. American Diabetes Association (ADA) Conference Abstracts. http://professional.diabetes.org/ Congress_Display.aspx?TYP=9\&CID=93229 (Accessed Nov 30, 2012).

17. European Association for the Study of Diabetes (EASD). http://www.easd.org/ (Accessed Nov 30, 2012).

18. International Diabetes Federation (IDF). http:// www.idf.org/worlddiabetescongress/welcome (Accessed Nov 30, 2012).

19. Canadian Diabetes Association (CDA). http://www. diabetes.ca/for-professionals/conference/montreal2013/ (Accessed Nov 30, 2012).

20. Health Technology Assessment International (HTAi). http://www.htai.org/ (Accessed Nov 30, 2012).
21. International Society for Pharmacoeconomics and Outcomes Research (ISPOR). http://www.ispor.org/ (Accessed Nov 30, 2012).

22. US National Institutes of Health (NIH). ClinicalTrials.gov. http://clinicaltrials.gov/ (Accessed Nov 30, 2012).

23. International Network of Agencies for Health Technology Assessment (INAHTA). http://www. inahta.org/HTA/ (Accessed Nov 30, 2012).

24. National Institute for Health and Care Excellence (NICE). http://www.nice.org.uk/ (Accessed Nov 30, 2012).

25. National Institute for Health Research (NIHR) HTA. http://www.hta.ac.uk/ (Accessed Nov 30, 2012).

26. Canadian Agency for Drugs and Technologies in Health. http://www.cadth.ca/ (Accessed Nov 30, 2012).

27. Institut für Qualität und Wirtschaftlichkeit im Gesundheitswesen (IQWiG). Allgemeine Methoden (Version 4.0); 2011.

28. l'Agence Nationale d'Accréditation et d'Evaluation en Santé (ANAES). Guide d'analyse de la litterature et gradation des recommendations. 2000 .

29. National Institute for Health and Care Excellence (NICE). Single technology appraisal (STA) template; 2012.

30. CONSORT. http://www.consort-statement.org/home/ (Accessed Nov, 2012).

31. Higgins JPT, Green S. Cochrane handbook for systematic reviews of interventions version 5.1.0 [updated March 2011]; 2011.

32. Lunn DJ, Best N, Thomas A, Wakefield J, Spiegelhalter D. Bayesian analysis of population PK/PD models: general concepts and software. J Pharmacokinet Pharmacodyn. 2002;29(3):271-307.

33. Dias S, Welton N, Sutton AJ, Caldwell DM, Lu G, Ades AE. NICE DSU Technical Support Document 4: inconsistency in networks of evidence based on randomised controlled trials; 2012.

34. Tajima N, Kadowaki T, Odawara M, Nishii M, Taniguchi T, Ferreira JCA. Addition of sitagliptin to ongoing glimepiride therapy in Japanese patients with type 2 diabetes over 52 weeks leads to improved glycemic control. Diabetol Int. 2011;2(1):32-44.

35. Bergenstal RM, Wysham C, Macconell L, et al. Efficacy and safety of exenatide once weekly versus 
sitagliptin or pioglitazone as an adjunct to metformin for treatment of type 2 diabetes (DURATION-2): a randomised trial. Lancet. 2010;376(9739):431-9.

36. Arnolds S, Dellweg S, Clair J, et al. Further improvement in postprandial glucose control with addition of exenatide or sitagliptin to combination therapy with insulin glargine and metformin: a proof-of-concept study. Diabetes Care. 2010;33(7):1509-15.

37. Barnett AH, Charbonnel B, Li J, Donovan M, Fleming D. Saxagliptin add-on therapy to insulin with or without metformin for type 2 diabetes mellitus: 52-week safety and efficacy. Diabetologia. 2011;54(Suppl 1):S108-9.

38. Barnett AH, Huisman H, Jones R, Von Eynatten M, Patel S, Woerle H. Efficacy and safety of linagliptin in elderly patients ( $>=70$ years) with type 2 diabetes. ADA. 2012;1017.

39. Göke B, Gallwitz B, Eriksson J, Bokelundsingh S, Gause-Nilsson I. Saxagliptin vs glipizide as add-on therapy to metformin for type 2 diabetes mellitus (T2DM): long-term safety and efficacy. Diabetes. 2011;60(Suppl 1):A305.

40. Kadowaki T, Tajima N, Odawara M, et al. Addition of sitagliptin, an oral, highly-selective dipeptidyl peptidase-4 inhibitor, improved glycemic control and was well tolerated in Japanese patients with type 2 diabetes on insulin monotherapy. Diabetes. 2011;60(Suppl 1):A279-80.

41. Koren S, Shemesh-Bar L, Tirosh A, et al. The effect of sitagliptin versus glibenclamide on arterial stiffness, blood pressure, lipids, and inflammation in type 2 diabetes mellitus patients. Diabetes Technol Ther. 2012;14(7):561-7.

42. Kothny W, Shao Q, Groop PH, Lukashevich V. Oneyear safety, tolerability and efficacy of vildagliptin in patients with type 2 diabetes and moderate or severe renal impairment. Diabetes Obes Metab. 2012;14(11):1032-9.

43. Ragonesi PD, Maffioli P, Cicero AFG, et al. Sitagliptin added to previously taken anti-diabetic agents on insulin-resistance and lipid profile: a two years study evaluation. Diabetologia. 2012;55(Suppl 1):S342-3.

44. Rhee EJ, Min KW, Jang HC, et al. Efficacy and safety of gemigliptin compared with sitagliptin added to ongoing metformin therapy in patients with type 2 diabetes inadequately controlled with metformin alone. Diabetologia. 2012;55(Suppl 1):S352.

45. Rosenstock J, Gross JL, Salinas CAA, et al. Long-term safety and efficacy of saxagliptin after 4-year follow- up of patients with type 2 diabetes. Diabetes. 2011;60(Suppl 1):A289-98.

46. Yang SJ, Min KW, Park JY, et al. Efficacy and safety of gemigliptin in patients with type 2 diabetes. Diabetologia. 2012;55(Suppl 1):S351-2.

47. Aschner P, Chan J, Owens DR, et al. Insulin glargine versus sitagliptin in insulin-naive patients with type 2 diabetes mellitus uncontrolled on metformin (EASIE): a multicentre, randomised open-label trial. Lancet. 2012;379(9833):2262-9.

48. Blonde L, Dagogo-Jack S, Banerji MA, et al. Comparison of vildagliptin and thiazolidinedione as add-on therapy in patients inadequately controlled with metformin: results of the GALIANT trial-a primary care, type 2 diabetes study. Diabetes Obes Metab. 2009;11(10):978-86.

49. Kim NH, Sung YA, Ahn CW, et al. Efficacy and safety of add-on vildagliptin to metformin in comparison to uptitrating metformin therapy. Diabetes. 2012;61(Suppl 1):A297.

50. Pratley RE, Nauck M, Bailey T. Liraglutide versus sitagliptin for patients with type 2 diabetes who did not have adequate glycaemic control with metformin: a 26-week, randomised, parallel-group, open-label trial. (vol 375, pg 1447, 2010). Lancet (North American Edition). 2010;376(9737):234.

51. Seino Y, Miyata Y, Hiroi S, Hirayama M, Kaku K. Efficacy and safety of alogliptin added to metformin in Japanese patients with type 2 diabetes: a randomized, double-blind, placebo-controlled trial with an open-label, long-term extension study. Diabetes Obes Metab. 2012;14(10):927-36.

52. Pfützner A, Paz-Pacheco E, Allen E, Frederich R, Chen R. Initial combination therapy with saxagliptin and metformin provides sustained glycaemic control and is well tolerated for up to 76 weeks. Diabetes Obes Metab. 2011;13(6):567-76.

53. Derosa G, Carbone A, Franzetti I, et al. Effects of a combination of sitagliptin plus metformin vs metformin monotherapy on glycemic control, b-cell function and insulin resistance in type 2 diabetic patients. Diabetes Res Clin Pract. 2012;98(1):51-60.

54. Pérez-Monteverde A, Seck T, Xu L, et al. Efficacy and safety of sitagliptin and the fixed-dose combination of sitagliptin and metformin vs. pioglitazone in drug-naïve patients with type 2 diabetes. Int J Clin Pract. 2011;65(9):930-8.

55. Wainstein J, Katz L, Engel SS, et al. Initial therapy with the fixed-dose combination of sitagliptin and metformin results in greater improvement in glycaemic control compared with pioglitazone 
monotherapy in patients with type 2 diabetes. Diabetes Obes Metab. 2012;14(5):409-18.

56. Jadzinsky M, Pfützner A, Paz-Pacheco E, Xu Z, Allen E, Chen R. Saxagliptin given in combination with metformin as initial therapy improves glycaemic control in patients with type 2 diabetes compared with either monotherapy: a randomized controlled trial. Diabetes Obes Metab. 2009;11(6):611-22.

57. Yoon KH, Shockey GR, Teng R, et al. Effect of initial combination therapy with sitagliptin, a dipeptidyl peptidase-4 inhibitor, and pioglitazone on glycemic control and measures of b-cell function in patients with type 2 diabetes. Int $\mathrm{J}$ Clin Pract. 2011;65(2):154-64.

58. Bosi E, Dotta F, Jia Y, Goodman M. Vildagliptin plus metformin combination therapy provides superior glycaemic control to individual monotherapy in treatment-naive patients with type 2 diabetes mellitus. Diabetes Obes Metab. 2009;11(5):506-15.

59. Derosa G, Ragonesi PD, Carbone A, et al. Vildagliptin added to metformin on b-cell function after a euglycemic hyperinsulinemic and hyperglycemic clamp in type 2 diabetes patients. Diabetes Technol Ther. 2012;14(6):475-84.

60. Goodman M, Thurston H, Penman J. Efficacy and tolerability of vildagliptin in patients with type 2 diabetes inadequately controlled with metformin monotherapy. Horm Metab Res. 2009;41(5):368-73.

61. Hong ES, Khang AR, Yoon JW, et al. Comparison between sitagliptin as add-on therapy to insulin and insulin dose-increase therapy in uncontrolled Korean type 2 diabetes: CSI study. Diabetes Obes Metab. 2012;14(9):795-802.

62. Kikuchi M, Haneda M, Koya D, et al. Efficacy and tolerability of vildagliptin as an add-on to glimepiride in Japanese patients with Type 2 diabetes mellitus. Diabetes Res Clin Pract. 2010;89(3):216-23.

63. Schweizer A, Dejager S, Bosi E. Comparison of vildagliptin and metformin monotherapy in elderly patients with type 2 diabetes: a 24-week, double-blind, randomized trial. Diabetes Obes Metab. 2009;11(8):804-12.

64. Bolli G, Dotta F, Rochotte E, Cohen SE. Efficacy and tolerability of vildagliptin vs. pioglitazone when added to metformin: a 24-week, randomized, double-blind study. Diabetes Obes Metab. 2008;10(1):82-90.

65. DeFronzo RA, Burant CF, Fleck P, Wilson C, Mekki Q, Pratley RE. Efficacy and tolerability of the DPP-4 inhibitor alogliptin combined with pioglitazone, in metformin-treated patients with type 2 diabetes. J Clin Endocrinol Metab. 2012;97(5):1615-22.

66. DeFronzo RA, Fleck PR, Wilson CA, Mekki Q. Efficacy and safety of the dipeptidyl peptidase-4 inhibitor alogliptin in patients with type 2 diabetes and inadequate glycemic control: a randomized, double-blind, placebo-controlled study. Diabetes Care. 2008;31(12):2315-7.

67. Dejager S, Razac S, Foley JE, Schweizer A. Vildagliptin in drug-naive patients with type 2 diabetes: a 24-week, double-blind, randomized, placebo-controlled, multiple-dose study. Horm Metab Res. 2007;39(3):218-23.

68. Eliasson B, Möller-Goede D, Eeg-Olofsson K, et al. Lowering of postprandial lipids in individuals with type 2 diabetes treated with alogliptin and/or pioglitazone: a randomised double-blind placebocontrolled study. Diabetologia. 2012;55(4):915-25.

69. Foley JE, Sreenan S. Efficacy and safety comparison between the DPP-4 inhibitor vildagliptin and the sulfonylurea gliclazide after two years of monotherapy in drug-naive patients with type 2 diabetes. Horm Metab Res. 2009;41(12):905-9.

70. Fonseca V, Schweizer A, Albrecht D, Baron MA, Chang I, Dejager S. Addition of vildagliptin to insulin improves glycaemic control in type 2 diabetes. Diabetologia. 2007;50(6):1148-55.

71. Garber AJ, Schweizer A, Baron MA, Rochotte E, Dejager S. Vildagliptin in combination with pioglitazone improves glycaemic control in patients with type 2 diabetes failing thiazolidinedione monotherapy: a randomized, placebo-controlled study. Diabetes Obes Metab. 2007;9(2):166-74.

72. Garber AJ, Foley JE, Banerji MA, et al. Effects of vildagliptin on glucose control in patients with type 2 diabetes inadequately controlled with a sulphonylurea. Diabetes Obes Metab. 2008;10(11):1047-56.

73. Lukashevich V, Schweizer A, Shao Q, Groop PH, Kothny W. Safety and efficacy of vildagliptin versus placebo in patients with type 2 diabetes and moderate or severe renal impairment: a prospective 24-week randomized placebocontrolled trial. Diabetes Obes Metab. 2011;13(10):947-54.

74. Nauck MA, Ellis GC, Fleck PR, Wilson CA, Mekki Q. Efficacy and safety of adding the dipeptidyl peptidase-4 inhibitor alogliptin to metformin therapy in patients with type 2 diabetes inadequately controlled with metformin monotherapy: a multicentre, randomised, double- 
blind, placebo-controlled study. Int J Clin Pract. 2009;63(1):46-55.

75. Pi-sunyer FX, Schweizer A, Mills D, Dejager S. Efficacy and tolerability of vildagliptin monotherapy in drug-naive patients with type 2 diabetes. Diabetes Res Clin Pract. 2007;76(1):132-8.

76. Rosenstock J, Kim SW, Baron MA, et al. Efficacy and tolerability of initial combination therapy with vildagliptin and pioglitazone compared with component monotherapy in patients with type 2 diabetes. Diabetes Obes Metab. 2007;9(2):175-85.

77. Rosenstock J, Inzucchi SE, Seufert J, Fleck PR, Wilson CA, Mekki Q. Initial combination therapy with alogliptin and pioglitazone in drug-naive patients with type 2 diabetes. Diabetes Care. 2010;33(11):2406-8.

78. Russell-Jones D, Cuddihy RM, Hanefeld M, et al. Efficacy and safety of exenatide once weekly versus metformin, pioglitazone, and sitagliptin used as monotherapy in drug-naive patients with type 2 diabetes (DURATION-4): a 26-week double-blind study. Diabetes Care. 2012;35(2):252-8.

79. World Health Organisation (WHO). The challenge of obesity in the WHO European Region and the strategies for response; 2014.

80. Barzilai N, Guo H, Mahoney EM, et al. Efficacy and tolerability of sitagliptin monotherapy in elderly patients with type 2 diabetes: a randomized, double-blind, placebo-controlled trial. Curr Med Res Opin. 2011;27(5):1049-58.

81. Fleck P, Wilson C, Rosenstock J. Similar glucose control over 52 weeks with alogliptin vs glipizide in older, mildly hyperglycaemic patients with type 2 diabetes. Diabetologia. 2012;55(Suppl 1):S347.

82. Derosa G, Maffioli P, Ferrari I, et al. Effects of one year treatment of vildagliptin added to pioglitazone or glimepiride in poorly controlled type 2 diabetic patients. Horm Metab Res. 2010;42(9):663-9.

83. Derosa G, Maffioli P, Salvadeo SA, et al. Effects of sitagliptin or metformin added to pioglitazone monotherapy in poorly controlled type 2 diabetes mellitus patients. Metabolism. 2010;59(6):887-95.

84. Seino Y, Fujita T, Hiroi S, Hirayama M, Kaku K. Efficacy and safety of alogliptin in Japanese patients with type 2 diabetes mellitus: a randomized, double-blind, dose-ranging comparison with placebo, followed by a long-term extension study. Curr Med Res Opin. 2011;27(9):1781-92.

85. Srivastava S, Saxena GN, Keshwani P, Gupta R. Comparing the efficacy and safety profile of sitagliptin versus glimepiride in patients of type 2 diabetes mellitus inadequately controlled with metformin alone. J Assoc Phys India. 2012;60:27-30.

86. Aaboe K, Knop FK, Visbøll T, et al. Twelve weeks treatment with the DPP-4 inhibitor, sitagliptin, prevents degradation of peptide YY and improves glucose and non-glucose induced insulin secretion in patients with type 2 diabetes mellitus. Diabetes Obes Metab. 2010;12(4):323-33.

87. Nonaka K, Tsubouchi H, Okuyama K, Fukao Y, Johnson-Levonas AO, Amatruda JM. Effects of oncedaily sitagliptin on 24-h glucose control following 4 weeks of treatment in Japanese patients with type 2 diabetes mellitus. Horm Metab Res. 2009;41(3):232-7.

88. Bosi E, Camisasca RP, Collober C, Rochotte E, Garber AJ. Effects of vildagliptin on glucose control over 24 weeks in patients with type 2 diabetes inadequately controlled with metformin. Diabetes Care. 2007;30(4):890-5.

89. DeFronzo RA, Hissa MN, Garber AJ, et al. The efficacy and safety of saxagliptin when added to metformin therapy in patients with inadequately controlled type 2 diabetes with metformin alone. Diabetes Care. 2009;32(9):1649-55.

90. Raz I, Chen Y, Wu M, et al. Efficacy and safety of sitagliptin added to ongoing metformin therapy in patients with type 2 diabetes. Curr Med Res Opin. 2008;24(2):537-50.

91. Kaku K, Itayasu T, Hiroi S, Hirayama M, Seino Y. Efficacy and safety of alogliptin added to pioglitazone in Japanese patients with type 2 diabetes: a randomized, double-blind, placebocontrolled trial with an open-label long-term extension study. Diabetes Obes Metab. 2011;13(11):1028-35.

92. Pratley RE, Kipnes MS, Fleck PR, Wilson C, Mekki Q. Efficacy and safety of the dipeptidyl peptidase- 4 inhibitor alogliptin in patients with type 2 diabetes inadequately controlled by glyburide monotherapy. Diabetes Obes Metab. 2009;11(2):167-76.

93. Del Prato S, Barnett AH, Huisman H, Neubacher D, Woerle HJ, Dugi KA. Effect of linagliptin monotherapy on glycaemic control and markers of b-cell function in patients with inadequately controlled type 2 diabetes: a randomized controlled trial. Diabetes Obes Metab. 2011;13(3):258-67.

94. Forst T, Uhlig-Laske B, Ring A, et al. Linagliptin (BI 1356), a potent and selective DPP-4 inhibitor, is safe and efficacious in combination with metformin in patients with inadequately controlled Type 2 diabetes. Diabet Med. 2010;27(12):1409-19. 
95. Gallwitz B, Rosenstock J, Rauch T, et al. 2-year efficacy and safety of linagliptin compared with glimepiride in patients with type 2 diabetes inadequately controlled on metformin: a randomised, double-blind, non-inferiority trial. Lancet (North American Edition). 2012;380(9840):475-83.

96. Gomis R, Espadero RM, Jones R, Woerle HJ, Dugi KA. Efficacy and safety of initial combination therapy with linagliptin and pioglitazone in patients with inadequately controlled type 2 diabetes: a randomized, double-blind, placebocontrolled study. Diabetes Obes Metab. 2011;13(7):653-61.

97. Haak T, Meinicke T, Jones R, Weber S, Von Eynatten $\mathrm{M}$, Woerle HJ. Initial combination of linagliptin and metformin improves glycaemic control in type 2 diabetes: a randomized, double-blind, placebocontrolled study. Diabetes Obes Metab. 2012;14(6):565-74.

98. Kawamori R, Inagaki N, Araki E, et al. Linagliptin monotherapy provides superior glycaemic control versus placebo or voglibose with comparable safety in Japanese patients with type 2 diabetes: a randomized, placebo and active comparatorcontrolled, double-blind study. Diabetes Obes Metab. 2012;14(4):348-57.

99. Lewin AJ, Arvay L, Liu D, Patel S, von Eynatten M, Woerle HJ. Efficacy and tolerability of linagliptin added to a sulfonylurea regimen in patients with inadequately controlled type 2 diabetes mellitus: an 18-week, multicenter, randomized, double-blind, placebo-controlled trial. Clin Ther. 2012;34(9):1909-19.

100. Owens DR, Swallow R, Dugi KA, Woerle HJ. Efficacy and safety of linagliptin in persons with type 2 diabetes inadequately controlled by a combination of metformin and sulphonylurea: a 24-week randomized study. Diabet Med. 2011;28(11):1352-61.

101. Ross SA, Rafeiro E, Meinicke T, Toorawa R, WeberBorn S, Woerle HJ. Efficacy and safety of linagliptin $2.5 \mathrm{mg}$ twice daily versus $5 \mathrm{mg}$ once daily in patients with type 2 diabetes inadequately controlled on metformin: a randomised, doubleblind, placebo-controlled trial. Curr Med Res Opin. 2012;28(9):1465-74.

102. Taskinen MR, Rosenstock J, Tamminen I, et al. Safety and efficacy of linagliptin as add-on therapy to metformin in patients with type 2 diabetes: a randomized, double-blind, placebo-controlled study. Diabetes Obes Metab. 2011;13(1):65-74.
103. Chacra AR, Tan GH, Apanovitch A, Ravichandran S, List J, Chen R. Saxagliptin added to a submaximal dose of sulphonylurea improves glycaemic control compared with uptitration of sulphonylurea in patients with type 2 diabetes: a randomised controlled trial. Int J Clin Pract. 2009;63(9):1395-406.

104. Fonseca V, Zhu T, Karyekar C, Hirshberg B. Adding saxagliptin to extended-release metformin vs. uptitrating metformin dosage. Diabetes Obes Metab. 2012;14(4):365-71.

105. Göke B, Gallwitz B, Eriksson J, Hellqvist A, GauseNilsson I. Saxagliptin is non-inferior to glipizide in patients with type 2 diabetes mellitus inadequately controlled on metformin alone: a 52-week randomised controlled trial. Int $\mathrm{J}$ Clin Pract. 2010;64(12):1619-31.

106. Pan CY, Yang W, Tou C, Gause-Nilsson I, Zhao J. Efficacy and safety of saxagliptin in drug-naïve Asian patients with type 2 diabetes mellitus: a randomized controlled trial. Diabetes Metab Res Rev. 2012;28(3):268-75.

107. Rosenstock J, Aguilar-Salinas C, Klein E, Nepal S, List J, Chen R. Effect of saxagliptin monotherapy in treatment-naive patients with type 2 diabetes. Curr Med Res Opin. 2009;25(10):2401-11.

108. Yang W, Pan CY, Tou C, Zhao J, Gause-Nilsson I. Efficacy and safety of saxagliptin added to metformin in Asian people with type 2 diabetes mellitus: a randomized controlled trial. Diabetes Res Clin Pract. 2011;94(2):217-24.

109. Arechavaleta R, Seck T, Chen Y, et al. Efficacy and safety of treatment with sitagliptin or glimepiride in patients with type 2 diabetes inadequately controlled on metformin monotherapy: a randomized, double-blind, non-inferiority trial. Diabetes Obes Metab. 2011;13(2):160-8.

110. Aschner P, Kipnes MS, Lunceford JK, Sanchez M, Mickel C, Williams-Herman DE. Effect of the dipeptidyl peptidase-4 inhibitor sitagliptin as monotherapy on glycemic control in patients with type 2 diabetes. Diabetes Care. 2006;29(12):2632-7.

111. Charbonnel B, Karasik A, Liu J, Wu M, Meininger G. Efficacy and safety of the dipeptidyl peptidase-4 inhibitor sitagliptin added to ongoing metformin 
therapy in patients with type 2 diabetes inadequately controlled with metformin alone. Diabetes Care. 2006;29(12):2638-43.

112. Goldstein BJ, Feinglos MN, Lunceford JK, Johnson J, Williams-Herman DE. Effect of initial combination therapy with sitagliptin, a dipeptidyl peptidase- 4 inhibitor, and metformin on glycemic control in patients with type 2 diabetes. Diabetes Care. 2007;30(8):1979-87.

113. Williams-Herman D, Johnson J, Teng R, et al. Efficacy and safety of initial combination therapy with sitagliptin and metformin in patients with type 2 diabetes: a 54-week study. Curr Med Res Opin. 2009;25(3):569-83.

114. Hanefeld M, Herman GA, Wu M, Mickel C, Sanchez M, Stein PP. Once-daily sitagliptin, a dipeptidyl peptidase-4 inhibitor, for the treatment of patients with type 2 diabetes. Curr Med Res Opin. 2007;23(6):1329-39.

115. Hermansen K, Kipnes M, Luo E, Fanurik D, Khatami $H$, Stein P. Efficacy and safety of the dipeptidyl peptidase-4 inhibitor, sitagliptin, in patients with type 2 diabetes mellitus inadequately controlled on glimepiride alone or on glimepiride and metformin. Diabetes Obes Metab. 2007;9(5):733-45.

116. Iwamoto Y, Tajima N, Kadowaki T, et al. Efficacy and safety of sitagliptin monotherapy compared with voglibose in Japanese patients with type 2 diabetes: a randomized, double-blind trial. Diabetes Obes Metab. 2010;12(7):613-22.

117. Nauck MA, Meininger G, Sheng D, Terranella L, Stein PP. Efficacy and safety of the dipeptidyl peptidase-4 inhibitor, sitagliptin, compared with the sulfonylurea, glipizide, in patients with type 2 diabetes inadequately controlled on metformin alone: a randomized, double-blind, non-inferiority trial. Diabetes Obes Metab. 2007;9(2):194-205.

118. Nonaka K, Kakikawa T, Sato A, et al. Efficacy and safety of sitagliptin monotherapy in Japanese patients with type 2 diabetes. Diabetes Res Clin Pract. 2008;79(2):291-8.

119. Reasner C, Olansky L, Seck TL, et al. The effect of initial therapy with the fixed-dose combination of sitagliptin and metformin compared with metformin monotherapy in patients with type 2 diabetes mellitus. Diabetes Obes Metab. 2011;13(7):644-52.

120. Scott R, Loeys T, Davies MJ, Engel SS. Efficacy and safety of sitagliptin when added to ongoing metformin therapy in patients with type 2 diabetes. Diabetes Obes Metab. 2008;10(10):959-69.

121. Ferrannini E, Fonseca V, Zinman B, et al. Fifty-twoweek efficacy and safety of vildagliptin vs. glimepiride in patients with type 2 diabetes mellitus inadequately controlled on metformin monotherapy. Diabetes Obes Metab. 2009;11(2):157-66.

122. Filozof C, Gautier JF. A comparison of efficacy and safety of vildagliptin and gliclazide in combination with metformin in patients with Type 2 diabetes inadequately controlled with metformin alone: a 52-week, randomized study. Diabet Med. 2010;27(3):318-26.

123. Kothny W, Kozlovski P, Foley J, Shao Q, Lukashevich V. Vildagliptin added to once or twice daily insulin regimens improves glycaemic control without increasing risk of hypoglycaemia and weight gain in patients with type 2 diabetes. Diabetologia. 2012;55(Suppl 1):S354.

124. Lukashevich V, Wang M, Del Prato S, Araga M, Kothny W. Vildagliptin efficacy and safety in patients with type 2 diabetes inadequately controlled on dual metformin plus sulfonylurea therapy. Diabetologia. 2012;55(Suppl 1):S353.

125. Matthews DR, Dejager S, Ahren B, et al. Vildagliptin add-on to metformin produces similar efficacy and reduced hypoglycaemic risk compared with glimepiride, with no weight gain: results from a 2-year study. Diabetes Obes Metab. 2010;12(9):780-9.

126. Pan C, Xing X, Han P, et al. Efficacy and tolerability of vildagliptin as add-on therapy to metformin in Chinese patients with type 2 diabetes mellitus. Diabetes Obes Metab. 2012;14(8):737-44.

127. Schweizer A, Couturier A, Foley JE, Dejager S. Comparison between vildagliptin and metformin to sustain reductions in $\mathrm{HbA}(1 \mathrm{c})$ over 1 year in drug-naive patients with Type 2 diabetes. Diabet Med. 2007;24(9):955-61. 